\title{
Dysregulation of DNA methylation patterns may identify patients with breast cancer resistant to endocrine therapy: A predictive classifier based on differentially methylated regions
}

\author{
FAN ZHANG and YUKUN CUI \\ Guangdong Provincial Key Laboratory for Breast Cancer Diagnosis and Treatment, \\ Cancer Hospital of Shantou University Medical College, Shantou, Guangdong 515041, P.R. China
}

Received May 5, 2018; Accepted April 15, 2019

DOI: $10.3892 / \mathrm{ol} .2019 .10405$

\begin{abstract}
Endocrine therapy (ET) is one of a number of targeted therapies for estrogen receptor-positive breast cancer (BRCA); however, resistance to ET has become the primary issue affecting treatment outcome. In the present study, a predictive classifier was created using a DNA methylation dataset to identify patients susceptible to endocrine resistance. DNA methylation and RNA sequencing data, and the clinicopathological features of BRCA, were obtained from The Cancer Genome Atlas. Stringent criteria were set to select and classify patients into two groups, namely those resistant to ET $(n=11)$ and sensitive to ET $(n=21)$ groups. Bump hunting analysis revealed that 502 out of 135,418 genomic regions were differentially methylated between these two groups; these regions were differentially methylated regions (DMRs). The majority of the CpG sites contained in the DMRs mapped to the promoter region. Functional enrichment analyses indicated that a total of 562 specific genes encompassing these DMRs were primarily associated with 'biological progress of organ morphogenesis and development' and 'cell-cell adhesion' gene ontologies. Logistic regression and Pearson's correlation analysis were conducted to construct a predictive classifier for distinguishing patients resistant or sensitive to ET. The highest areas under the curve and relatively low Akaike information criterion values were associated with a total of $60 \mathrm{DMRs}$; a risk score retained from this classifier was revealed to be an unfavorable predictor of survival in two additional independent datasets. Furthermore, the majority of genes $(55 / 63)$ exhibited a statistically significant association between DNA methylation and mRNA expression $(\mathrm{P}<0.05)$. The association
\end{abstract}

Correspondence to: Professor Yukun Cui, Guangdong Provincial Key Laboratory for Breast Cancer Diagnosis and Treatment, Cancer Hospital of Shantou University Medical College, 7 Raoping Road, Shantou, Guangdong 515041, P.R. China

E-mail: yukuncui@yahoo.com

Key words: breast cancer, DNA methylation, differentially methylated regions, resistance to endocrine therapy, predictive classifier between the mRNA expression of a number of genes (namely calcium release activated channel regulator $2 \mathrm{~A}$, Schlafen family member 12 , chromosome 3 open reading frame 18 , zinc finger protein 880 , dual oxidase 1, major histocompatibility complex, class II, DP $\beta 1, \mathrm{C}$-terminal binding protein 1 , ALG13 UDP-N-acetylglucosaminyltransferase subunit and RAS protein activator like 2) and the prognosis of patients with estrogen receptor-positive BRCA and ET resistance was determined using Kaplan-Meier Plotter. In summary, the predictive classifier proposed in the present study may aid the identification of patients sensitive or resistant to ET, and numerous genes maybe potential therapeutic targets to delay the development of resistance to ET.

\section{Introduction}

Breast cancer (BRCA) is the most common type of cancer in women globally (1) and is characterized by notable heterogeneity (2). The expression levels of estrogen and progesterone receptors (ER/PR) and human epidermal growth factor receptor (HER2) have been investigated to further classify BRCA into numerous subtypes: Luminal $\left(\mathrm{ER}^{+} / \mathrm{PR}^{+}\right)$, HER2-positive $\left(\mathrm{ER}^{-} / \mathrm{PR}^{-} / \mathrm{HER} 2^{+}\right)$, basal-like or triple negative (ER $/ \mathrm{PR}^{-} / \mathrm{HER}^{-}$), claudin-low and normal-like BRCA (3). Based on these guidelines (4), $270 \%$ of patients with BRCA may be classified as the luminal subtype (5). Endocrine therapy (ET), one of the crucial adjuvant treatments for luminal BRCA, suppresses tumor growth by targeting the ER signaling pathways. Unfortunately, $>30 \%$ of ER-positive tumor types are intrinsically endocrine-resistant at diagnosis; $\sim 40 \%$ of breast tumor types that initially respond to ET eventually acquire resistance (6). Additionally, the clinical characteristics of BRCA may be notably heterogeneous even when similar expression levels of ER are observed (7).

ET resistance in ER-positive tumor cells may be ascribed to a variety of factors, including the post-transcriptional modifications of ERs $(8,9)$ or activation of the ER-independent growth factor signaling pathways (10); however, these results have not been further investigated for the effective clinical treatment of BRCA $(11,12)$. Upon metastasis, surgical intervention and present second-line therapeutic strategies have 
limited effectiveness. Thus, precisely predicting the prognosis of patients with BRCA and ET resistance is vital for generating the most appropriate individualized treatment.

As ER status alone is inadequate for identifying patients responsive to ET, multi-gene signatures from gene transcripts have been obtained via analyses with Oncotype DX (13) and MammaPrint tests (14). The expression profiles of these biomarkers may substantially aid the prediction of therapeutic outcomes and the selection of adjuvant therapy (3); however, transcriptional expression may be regulated by a variety of factors and appears to be unstable. Additionally, gene transcripts may not reflect marked changes in regulatory mechanisms, including epigenetic alterations, which may result in disease susceptibility. This represents a limitation of current molecular diagnostic tools based on gene expression assays (15).

DNA methylation is a chemical modification of DNA that does not result in alterations in its sequence and may be inherited during cell division. It is well established that notable alterations to the genome-wide DNA methylation landscape may occur in the early stages of cancer initiation and during cancer progression, and throughout the acquisition of drug resistance $(16,17)$. The hypermethylation of tumor suppressor genes or the hypomethylation of oncogenes maybe associated with the development of $\operatorname{BRCA}(18,19)$. DNA methylation is an enzymatic process and may be reversed by epigenetic inhibitors (17). Compared with genetic transcription (mRNA), DNA is inherently stable and may be obtained from numerous sources, including tissue, plasma, saliva and urine (20). Therefore, the DNA methylation profile is promising for identifying patients susceptible to ET. In addition, specific epigenotypes have been identified for the characterization and molecular subtyping of BRCA (21-23); however, few studies focusing on the DNA methylome associated with endocrine-resistant BRCA have been conducted. Furthermore, previous studies have revealed that remodeling of the epigenome is associated with the endocrine-resistant cell phenotype $(24,25)$. Thus, DNA methylation signatures may serve as predictive biomarkers to identify ET-responsive patients with BRCA.

DNA methylation levels maybe simultaneously determined via microarray analyses of numerous CpGs. An increasing number of genome-wide DNA methylation profiles of various types of cancer are available from public databases (26). Previous studies have revealed the importance of methylation in genomic regions compared with that at a single $\mathrm{CpG}$ island $(27,28)$. A genome-wide bump hunting approach, introduced by Jaffe et al (29), was originally designed to identify differentially methylated regions (DMRs) detected on numerous microarray platforms, including the Infinium HumanMethylation450 BeadArray (HM450 array). This approach was demonstrated to effectively model expression profiles without measurement errors, remove batch effects and detect regions of interest. The present study aimed to identify a novel predictive classifier of BRCA by applying the bump hunting method and logistic regression to The Cancer Genome Atlas (TCGA) BRCA datasets on the basis of the DNA methylation profile of BRCA. The results of the present study may aid the identification of patients susceptible to endocrine resistance.

\section{Materials and methods}

Data downloading and processing. The DNA methylation profiles associated with BRCA were determined using an HM450 array; the corresponding RNA sequencing data (IlluminaHiSeq_RNASeqV2 arrays; measured using RSEM software; version 1.2.31) (30) and detailed clinicopathological features, including ET information, were downloaded from TCGA (accessed: January 2016; known as the Genomic Data Common Data Portal; https://portal.gdc.cancer.gov/); there were a total of 885 and 1,213 tumor/adjacent tissues with DNA methylation and RNA sequencing data, respectively. Among them, 787 tumor/adjacent tissues possessed both DNA methylation and RNA sequencing data. These samples were used to examine the association between DNA methylation and mRNA expression for the DMRs included in the predictive classifier. Additionally, two DNA methylation datasets based on HM450 array analysis, namely GSE75067 (31) and GSE72251 (32) from the Gene Expression Omnibus database (33) (http://www.ncbi.nlm.nih.gov/geo/), were used as independent datasets to assess the predictive potential of DNA methylation as a classifier of endocrine resistance.

Patient enrollment. In order to investigate the DNA methylation patterns associated with sensitivity to ET, inclusion criteria for patient enrollment were set. In the present study, all patients were: i) Diagnosed with BRCA; ii) female and $\leq 75$-year-old; iii) positive for tumor types of tumor, node and metastasis (TNM) stage <4 $(34,35)$ and ER $\alpha$ expression; and iv) treated with ET. Consequently, of the 1,097 patients with BRCA, 404 patients were selected. Of these patients, those with disease free survival (DFS) $\leq 30$ months were regarded to resist ET and were defined as the resistant to ET (RTE) group. Those with DFS >100 months were classified as the sensitive to ET (STE) group; patients without DNA methylation data were excluded. Furthermore, there were 11 and 21 patients in the RTE and STE groups, respectively; the data of these patients were included for the predictive classifier building. Either a Fisher's exact test or a Student's t-test were conducted to determine differences of clinicopathological features between these two groups.

Model construction and selection. The level 3 DNA methylation $\beta$-value of BRCA from TCGA was defined as the percentage of DNA methylation in the tissue samples at each $\mathrm{CpG}$ probe; the methylation ranged from 0.0 (unmethylated) to 1.0 (fully methylated). In the present study, the M-value $[\operatorname{logit}(\beta)]$ was used instead of the $\beta$-value to calculate the test statistics; however, for ease of interpretation, the $\beta$-value was employed to report differences in methylation levels between the groups. The association between $\mathrm{M}$ - and $\beta$-values were determined as follows: $M$-value $=\log _{2}[\beta$-value $/(1-\beta$-value $)]$.

For the identification of DMRs, CpG sites that did not target specific genes and sites without data in any patients were excluded. Additionally, differential expression analysis was conducted to reveal the DMRs between the RTE and SET groups with the R-package 'bumphunter' (version 1.10.0) (29). This package was used to determine regions of methylation that deviated from the baseline values. DMRs were defined as genomic regions of differential methylation between 
two populations with a $\mathrm{P}$-value $<0.001$ and covering $\geq 3 \mathrm{CpG}$ sites. The diagnostic potential of these DMRs was further investigated by producing receiver operating characteristic curves (ROCs) and calculating the area under the curve (AUC). The median $\beta$-value across the $\mathrm{CpG}$ sites in each DMR $\left(m_{S}\right)$ was calculated and the difference of $m_{S}$ between the two groups $(d)$ was determined. Finally, DMRs with an AUC $\geq 0.6$ and $|d|>0.2$ were included to build the predictive classifier, and were ranked in an ascending order of P-values obtained from the bumphunter analysis.

In the first step of the classifier building, 3 DMRs per analysis were added into the predictive classifier. The mean $m_{S}$ of each DMR across all patients in the STE group, representing relatively normal DNA methylation, was calculated as $m_{R}$. In the second step, a Pearson's correlation coefficient was calculated between the $m_{R}$ and $m_{S}$ of each patient, labeled as the $r_{P}$ value (-1 to 1 ). A positive $r_{P}$ value represented the expression profile, indicating an association with patients in the STE group; otherwise, the expression profile of patients was considered to be less associated with the STE group. In step three, the effect of $r_{P}$ values on the prediction of patients with ER-positive BRCA resistant to ET was evaluated via the logistic regression analysis; the predictive classifier was then generated. Simultaneously, ROCs in addition to the AUC were used to assess the diagnostic potential of the predictive classifier. A 95\% confidence interval (CI) of the AUC was calculated according to the order of the observed AUC values among 1,000 permutations. Finally, for the model selection, the Akaike information criterion (AIC) was used to determine the goodness of fit and the simplicity of the classifier. As aforementioned, 3 DMRs were included each time and the process (steps 1-3) was repeated until all 80 DMRs were included. A risk score (RS) was then able to be calculated based on the final classifier.

Model validation. As public datasets with both DNA methylation (determined via an HM450 array) and treatment information were unavailable, patients with ER-positive BRCA without explicit information regarding ET were used. The independent datasets, GSE75067 and GSE72251, which determined DNA methylation in 87 and 70 patients with ER-positive BRCA, respectively, were used as external validations of the predictive classifier. An RS was assigned to each patient; Kaplan-Meier (KM) survival analysis was then performed to investigate the association between RS and cumulative rates of overall survival (OS) and invasive disease-free survival (IDFS). As for GSE75067, univariate and multivariate analyses using Cox regressions were also performed to screen out the independent factors affecting OS.

Identification of the function of genes included in DMRs. Functional enrichment analysis was performed using the R-package 'clusterProfiler' (version 3.6.0) (36) to investigate the well-known database, Gene Ontology (GO; http://geneontology.org/) (37,38). The specific genes, which were mapped by DMR analysis, were annotated with GO 'biological process' (BP), 'molecular function' (MF) and 'cellular component' (CC) terms. GO terms of $\mathrm{P}<0.01$ and $\mathrm{P}_{\mathrm{a}}<0.05$ obtained via the Benjamini and Hochberg method (39) were considered to be statistically enriched.
Correlation between DNA methylation and mRNA transcripts. Pearson's correlation coefficients were further calculated to reveal the correlation between DNA methylation and mRNA expression. Since the sample sizes of the groups were limited, the data of 787 tumor/adjacent tissues in the TCGA dataset were employed for the correlation analysis. Since one DMR could contain several CpG sites mapped to one specific gene, several Pearson's correlation analyses were conducted separately to examine the associations between these $\mathrm{CpG}$ sites and the mRNA level of the gene. The $\mathrm{CpG}$ site in a specific DMR with the lowest P-value was demonstrated to exhibit the strongest correlation with the mRNA expression, and presented.

Effects of numerous specific genes on relapse-free survival (RFS). KM Plotter (http://kmplot.com/analysis/) (40,41), a tool containing the gene expression and survival data of $>4,000$ patients with BRCA, was used to perform KM survival analyses to further assess the association between mRNA expression and RFS. Patients with ER-positive BRCA and ET were selected, and divided into the high and low expression groups based on the median expression levels of each specific gene. Subsequently, survival curves were created and log-rank tests were conducted.

\section{Results}

Identification of DMRs associated with the response to ET in patients with ER-positive BRCA. As presented in Fig. 1A, patients with BRCA meeting the inclusion criteria were divided into two groups according to their DFS, namely the RTE and STE groups. Detailed clinicopathological and treatment information of these 32 patients were presented in Table I. Of them, five patients had received tamoxifen, while 14 patients had been treated with aromatase inhibitors (anastrozole, letrozole and aromasin). The remaining patients were treated with one type of these drugs for a period of time, and subsequently treated with another type. A Fisher's exact test and a Student's t-test were conducted to determine differences between these two groups. No statistically significant differences in TNM stage and receptors status were observed between the two groups. In the RTE group, the tumor types of eight patients $(8 / 11,72.7 \%)$ were TNM stage II and three $(3 / 11,27.3 \%)$ were TNM stage III; however, in the STE group, five $(5 / 21,23.8 \%)$, $12(12 / 21,57.1 \%)$ and four $(4 / 21,19.0 \%)$ tumor types were classified as TNM I, II and III stages $(\mathrm{P}=0.205)$, respectively. As for receptor status, nine tumor types $(9 / 11,81.8 \%)$ from the RTE group and $16(16 / 21,76.2 \%)$ tumor types from the STE group were PR-positive $(\mathrm{P}=1.000)$. In addition, only two tumor types $(2 / 11,18.2 \%)$ from the RTE group and two tumor types $(2 / 21,9.5 \%)$ from the STE group expressed HER-2 $(\mathrm{P}=0.738)$. The mean age of the patients in the RTE groups was slightly higher compared with that of the patients in the STE group; no statistical significance was observed $(\mathrm{P}=0.235)$. Based on the aforementioned results, the clinicopathological data of these two groups were comparable.

Aberrant methylation profiles of DMRs were identified between the RTE and STE groups (Fig. 1B). Genomic locations were grouped into clusters (regions) based on a maximum distance of 500 base pairs (bp); of the 135,418 genomic 

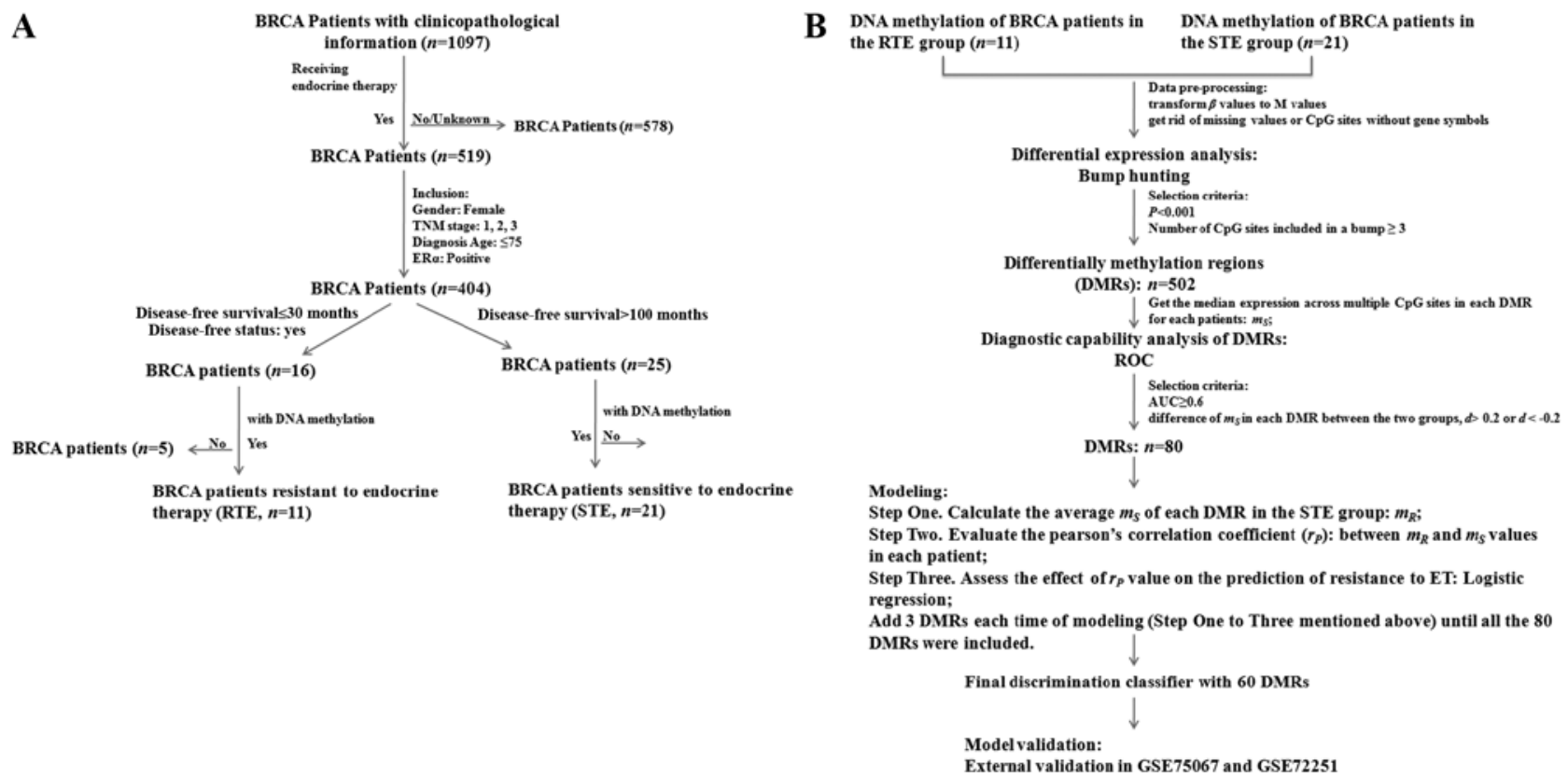

Figure 1. Flow chart of patient selection and model construction. (A) Publicly available DNA methylation, RNA sequence and clinicopathological features of BRCA were downloaded from The Cancer Genome Atlas. Stringent criteria were set to select and classify patients into two groups, namely the RTE $(\mathrm{n}=11)$ group and the STE $(\mathrm{n}=21)$ group. (B) Bump hunting was used to identify DMRs, which was used to construct a predictive classifier. The final classifier had 60 DMRs and was validated in an independent dataset (GSE75067). BRCA, breast cancer; TNM, Tumor Node Metastasis; ER $\alpha$, estrogen receptor $\alpha$; RTE, resistant to endocrine therapy; STE, sensitive to endocrine therapy; ROC, receiver operating characteristic; AUC, area under the curve; DMR, differentially methylated regions; ET, endocrine therapy.

regions, 502 regions, including 5,252 CpG sites were significantly differently methylated $(\mathrm{P}<0.001)$ and had $\geq 3$ individual CpG sites (Fig. 2A). Due to the limited sample sizes of these two groups, multiple testing correction was not conducted. Of the 502 DMRs, the median size was $803 \mathrm{bp}$, with a range of 41-3,509 bp; the median number of CpGs in each DMR was 10 , with a range of 3-32. According to the annotation files, the majority of the $5,252 \mathrm{CpG}$ sites were mapped to the promoter region (TSS1500 and TSS200), the gene body and the 5'-untranslated region (UTR) and 3'-UTR, in addition to the first exon (Fig. 2B). Of note, each CpG site may simultaneously be detected in the promoter and other regions due to the various transcripts of a specific gene. These 502 DMRs encompassed 562 specific genes, and genes in the top ranked 20 DMRs were calcium release activated channel regulator $2 \mathrm{~A}$ (EFCAB4B), paraoxonase 3, homeobox C4 (HOXC4), podoplanin (PDPN), major histocompatibility complex, class II, DQ $\beta 2$, helt bHLH transcription factor, major histocompatibility complex, class I, J (pseudogene)/zinc ribbon domain containing 1 antisense, pseudogene, proline rich transmembrane protein $1 /$ palmitoyl-protein thioesterase 2 , family with sequence similarity 24 member B/chromosome 10 open reading frame 88 pseudogene, achaete-scute family bHLH transcription factor 2, histone cluster $1 \mathrm{H} 4$ family member L/histone cluster $1 \mathrm{H} 3$ family member I, tenascin XB, EYA transcriptional coactivator and phosphatase 4, lymphotoxin $\alpha$, epithelial stromal interaction 1 (EPSTI1), dimethylarginine dimethylaminohydrolase 2 , GATA binding protein 5 , heparan sulfate-glucosamine 3 -sulfotransferase 1, major histocompatibility complex, class II, DO $\alpha$ and homeobox C8 (HOXC8) (genes in the top ranked 50 DMRs were listed in Table II). Functional enrichment analysis was performed on these genes. Consequently, $48 \mathrm{BP}, 8 \mathrm{MF}$ and only one CC GO terms were significantly enriched with a P-value $<0.01$ and a false discovery rate q-value $<0.05$ (Fig. 2C-E). The top-ranked representative $10 \mathrm{BP}$ GO terms were 'skeletal system development' $\left(\mathrm{P}=6.24 \times 10^{-7}\right)$, 'cell-cell adhesion via plasma-membrane adhesion molecules' $\left(\mathrm{P}=1.64 \times 10^{-15}\right)$, 'homophilic cell adhesion via plasma membrane adhesion molecules' $\left(\mathrm{P}=9.51 \times 10^{-21}\right)$, 'pattern specification process' $\left(\mathrm{P}=7.88 \times 10^{-7}\right)$, 'embryonic organ morphogenesis' $\left(\mathrm{P}=1.86 \times 10^{-6}\right)$, 'gland development' $\left(\mathrm{P}=6.45 \times 10^{-7}\right)$, 'forebrain development' $\left(\mathrm{P}=9.95 \times 10^{-8}\right)$, 'regulation of hormone levels' $\left(\mathrm{P}=5.88 \times 10^{-5}\right)$, 'cell fate commitment' $\left(\mathrm{P}=4.35 \times 10^{-11}\right)$ and 'muscle organ development' $\left(\mathrm{P}=2.19 \times 10^{-5}\right)$. The associated genes are listed in Table III, including the HOX family of genes, such as HOXC4 and HOXC8, the protocadherin (PCDH) $\alpha$ gene cluster, such as PCDHA4, PCDHA7, PCDHA10, PCDH8 and PCDHGA1, and other genes known to affect the tumor growth and metastasis [including C-X-C motif chemokine ligand 12, SRY-box 2, E74 like ETS transcription factor 5 (ELF5), epidermal growth factor receptor, tumor necrosis factor and fibroblast growth factor receptor 1 , etc.]. Additionally, these genes were significantly associated with the MF GO terms of 'protein heterodimerization activity' $\left(\mathrm{P}=1.34 \times 10^{-4}\right)$, 'transcription factor activity, RNA polymerase II core promoter proximal region sequence-specific binding' $\left(\mathrm{P}=1.10 \times 10^{-6}\right)$, 'transcriptional activator activity, RNA polymerase II transcription regulatory region sequence-specific binding' $\left(\mathrm{P}=5.79 \times 10^{-7}\right)$, 'transcriptional activator activity, RNA polymerase II core promoter proximal region sequence-specific binding' $\left(\mathrm{P}=3.85 \times 10^{-5}\right)$, 'glucuronosyltransferase activity' $\left(\mathrm{P}=1.38 \times 10^{-7}\right)$, 'retinoid binding' $\left(\mathrm{P}=1.21 \times 10^{-4}\right)$, 'retinoic acid binding' $\left(\mathrm{P}=2.77 \times 10^{-6}\right)$ and 'oxidoreductase activity and acting on $\mathrm{NAD}(\mathrm{P}) \mathrm{H}$, oxygen 


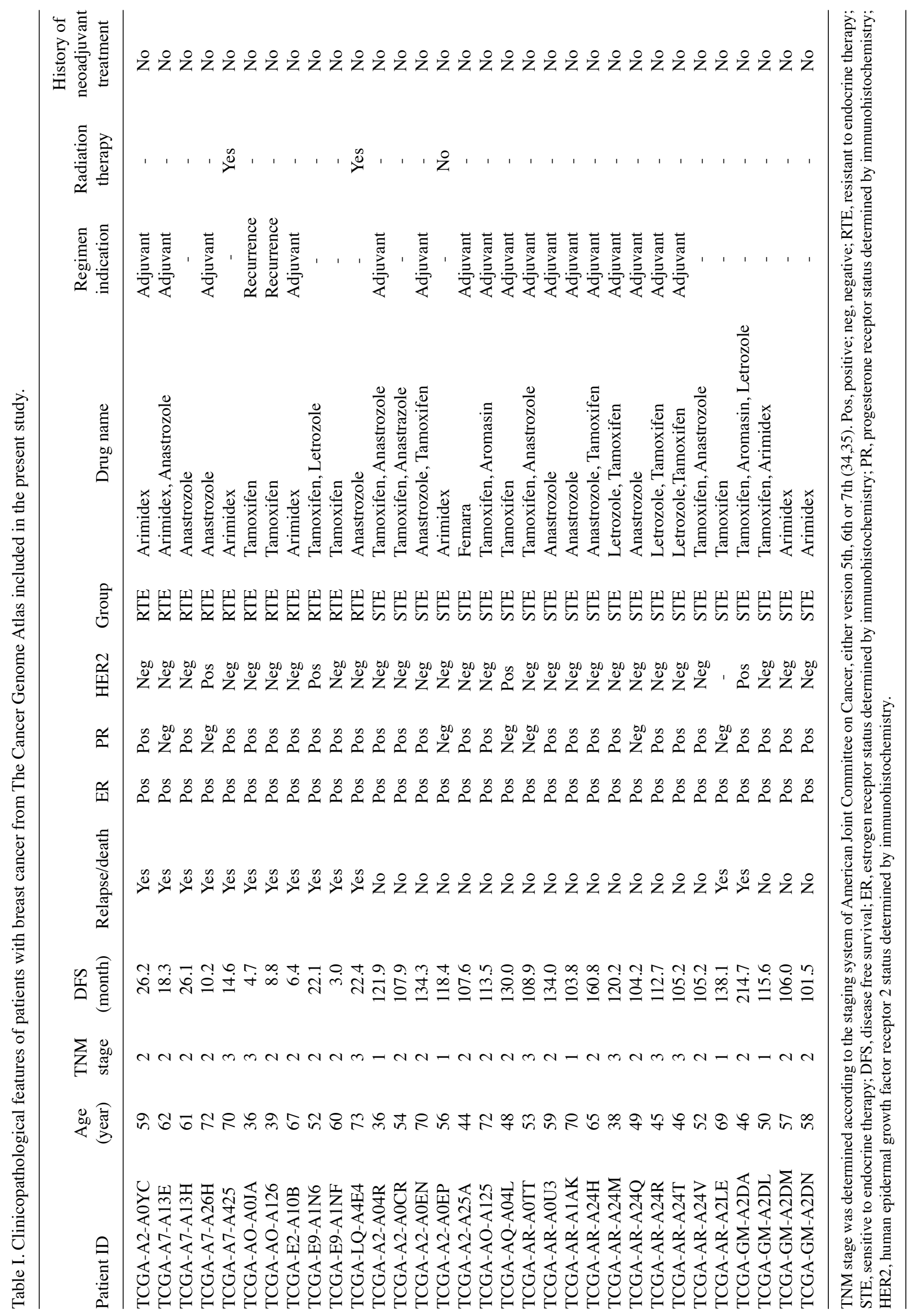



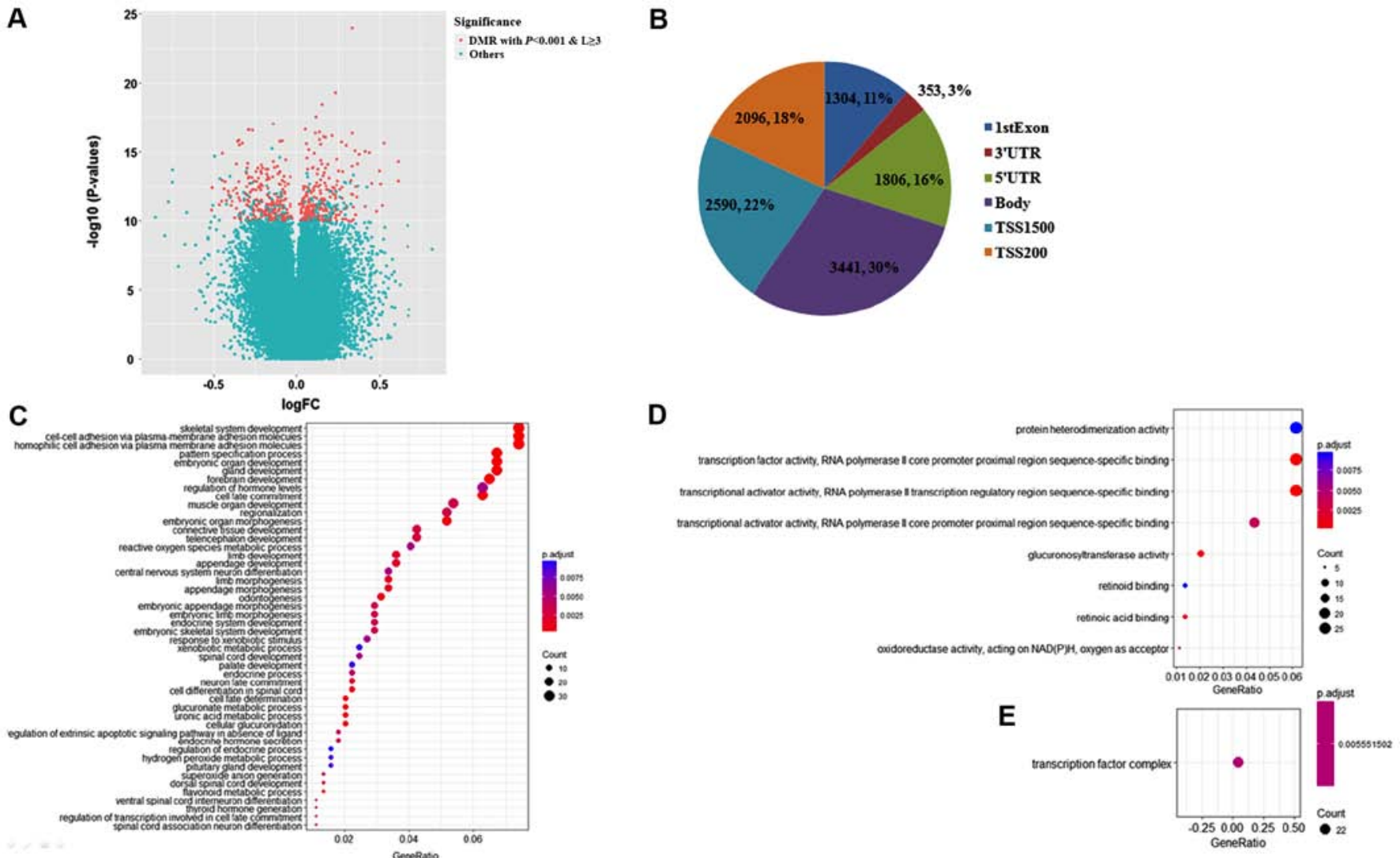

Figure 2. Identification of DMRs by bump hunting. (A) DMRs were defined as the genomic regions differentially methylated between two populations at a $\mathrm{P}$-value $<0.001$ (retained from bump hunting) and covering $\geq 3 \mathrm{CpG}$ sites. In total, 502 out of 135,418 genomic regions were regarded as DMRs and represented as red points in the volcano plot, while other genomic regions were indicated as blue points. The $\mathrm{x}$-axis represented the log-transformed FC of the $\beta$-value between the resistant to endocrine therapy group and the sensitive to endocrine therapy group, and the y-axis represented the log-transformed P-value retained from bump hunting. (B) Pie chart indicating the location of 5,252 CpG sites enclosed in these DMRs. As observed, the majority of the CpG sites mapped into the promoter region (TSS1500 and TSS200), and then the gene body, followed by the 5'UTR and 3'UTR and 1st Exon. Gene Ontology (C) Biological Process, (D) Molecular Function and (E) Cellular Component terms were enriched by 562 specific genes encompassed by DMRs. FC, fold change; DMR, differentially methylated regions; UTR, untranslated region.

as acceptor' $\left(\mathrm{P}=3.85 \times 10^{-5}\right)$. The only significant $\mathrm{CC}$ GO term was 'transcription factor complex' $\left(\mathrm{P}=1.31 \times 10^{-5}\right)$.

Classifier building for predicting the response to ET in patients with ER-positive BRCA based on DMR patterns. Following the process presented in Fig. 1B, 502 DMRs were identified, of which 457 DMRs had an AUC $\geq 0.6$. Finally, 80 DMRs remained to build the predictive classifier set (with a difference of $m_{S}$ between the RTE and STE groups $>0.2$ ).

As presented in Fig. 3A, the logistic regression, including 60 DMRs, had the highest AUC to distinguish the RTE group from the STE group, and a relatively low AIC to indicate the goodness of fit and the simplicity of the classifier. Therefore, these 60 DMRs listed in Table IV were included. Among them, 31 DMRs, including EFCAB4B, secretoglobin family $3 \mathrm{~A}$ member 1 (SCGB3A1) and dual oxidase maturation factor 1 (DUOXA1), were hypermethylated in the RTE group, and the remaining DMRs, including tripartite motif containing 58 and ELF5, were hypomethylated in the RTE group. Unsupervised hierarchical clustering analysis of these patients in the RTE and STE groups was performed based on these 60 DMRs. As presented in Fig. 3B, patients were divided into two classes, as follows: Class 1 was mainly enriched for patients in the STE group (20/21), while class 2 comprised 10 patients in the RTE group and one in the STE group. In total, only two samples $(2 / 32,6.25 \%)$ were incorrectly sorted into the wrong group.

Based on the aforementioned 60 DMRs, an equation based on the aforementioned logistic regression, $\ln (\mathrm{p} / 1-\mathrm{p})=7.207-12.610 x$, was generated to evaluate the probability of resistance to ET in patients with ER-positive BRCA. The denoting of letters in the equation is as follows: $p$, the probability of resistance to ET, and $x, r_{P}$ values between $m_{R}$ and $m_{S}$ across 60 DMRs in each patient. Thus, the RS was generated and described as follows: $\mathrm{RS}=\mathrm{e}^{7.207-12.610 x} /\left(1+\mathrm{e}^{7.207-12.610 x}\right)$.

Application of $R S$ on the prognosis of patients with ER-positive BRCA in two additional independent test datasets. The GSE75067 dataset containing the data of 87 patients with ER-positive BRCA was used instead to externally analyze the prognostic power of the RS on BRCA. The RS of each ER-positive patient was calculated; the median RS among these patients was 0.161 , with a range of 0.051-0.982. As observed in Fig. 3C and D, whether the cutoff value of RS was 0.2 or 0.5 , patients with higher RS values tended to exhibit significantly shorter OS times compared with those with lower RS values (log-rank test, $\mathrm{P}=0.042$ and $\mathrm{P}<0.001$, respectively). Furthermore, Cox regression analysis 
Table II. DMRs between patients resistant and sensitive to endocrine therapy.

\begin{tabular}{|c|c|c|c|c|c|c|}
\hline Bumps (no.) & Chr & $\begin{array}{c}\text { Start coordinate } \\
\text { of DMR }\end{array}$ & $\begin{array}{c}\text { End coordinate } \\
\text { of DMR }\end{array}$ & Gene(s) & $\begin{array}{c}\text { Number of CpGs } \\
\text { in DMR }\end{array}$ & $\begin{array}{c}\text { DMR } \\
\text { P-value }\end{array}$ \\
\hline 23474 & 12 & 3862221 & 3862597 & EFCAB4B & 12 & $1.28 \times 10^{-5}$ \\
\hline 95719 & 7 & 95025194 & 95026937 & PON3 & 25 & $1.46 \times 10^{-5}$ \\
\hline 25363 & 12 & 54446100 & 54448913 & $\mathrm{HOXC} 4$ & 26 & $2.21 \times 10^{-5}$ \\
\hline 2013 & 1 & 13909161 & 13910796 & PDPN & 17 & $2.35 \times 10^{-5}$ \\
\hline 88062 & 6 & 32729174 & 32730299 & HLA-DQB2 & 31 & $3.60 \times 10^{-5}$ \\
\hline 81042 & 4 & 185938933 & 185941625 & HELT & 23 & $4.27 \times 10^{-5}$ \\
\hline 87538 & 6 & 29974022 & 29975078 & HLA-J;NCRNA00171 & 32 & $4.52 \times 10^{-5}$ \\
\hline 87958 & 6 & 32119616 & 32121249 & PRRT1;PPT2 & 32 & $4.96 \times 10^{-5}$ \\
\hline 15619 & 10 & 124638756 & 124639892 & FAM24B;LOC399815 & 19 & $5.27 \times 10^{-5}$ \\
\hline 16983 & 11 & 2291347 & 2292905 & ASCL2 & 22 & $6.87 \times 10^{-5}$ \\
\hline 87359 & 6 & 27840957 & 27842098 & HIST1H4L;HIST1H3I & 16 & $8.00 \times 10^{-5}$ \\
\hline 87946 & 6 & 32063774 & 32064749 & TNXB & 31 & $8.77 \times 10^{-5}$ \\
\hline 90707 & 6 & 133561614 & 133562196 & EYA4 & 19 & $9.02 \times 10^{-5}$ \\
\hline 87773 & 6 & 31539601 & 31540750 & LTA & 18 & $9.29 \times 10^{-5}$ \\
\hline 29316 & 13 & 43565901 & 43566902 & EPSTI1 & 14 & $9.85 \times 10^{-5}$ \\
\hline 87830 & 6 & 31695903 & 31697276 & DDAH2 & 32 & $9.90 \times 10^{-5}$ \\
\hline 66889 & 20 & 61050560 & 61051561 & GATA5 & 15 & $1.00 \times 10^{-4}$ \\
\hline 77952 & 4 & 11430022 & 11431359 & HS3ST1 & 12 & $1.03 \times 10^{-4}$ \\
\hline 88100 & 6 & 32975875 & 32978129 & HLA-DOA & 24 & $1.27 \times 10^{-4}$ \\
\hline 25345 & 12 & 54402431 & 54403314 & HOXC8 & 12 & $1.42 \times 10^{-4}$ \\
\hline 12810 & 10 & 50969997 & 50970591 & OGDHL & 11 & $1.71 \times 10^{-4}$ \\
\hline 17099 & 11 & 2890019 & 2891118 & KCNQ1DN & 30 & $1.74 \times 10^{-4}$ \\
\hline 84428 & 5 & 140305713 & 140306458 & PCDHAC1; PCDHA7; & 11 & $1.80 \times 10^{-4}$ \\
\hline
\end{tabular}

$\begin{array}{lrrr}16989 & 11 & 2397201 & 2397977 \\ 36576 & 15 & 72667883 & 72669149 \\ 84434 & 5 & 140345966 & 140346403\end{array}$

$\begin{array}{lrrr}23388 & 12 & 2800055 & 2801584 \\ 16985 & 11 & 2321770 & 2323059 \\ 46839 & 17 & 46655164 & 46656543 \\ 5778 & 1 & 92951355 & 92952268 \\ 83500 & 5 & 112073348 & 112073769 \\ 26639 & 12 & 103351180 & 103352454 \\ 109271 & \mathrm{X} & 153236083 & 153238579 \\ 78985 & 4 & 76555547 & 76556042 \\ 42578 & 16 & 88717134 & 88717989 \\ 107070 & \mathrm{X} & 16729564 & 16731095 \\ 80825 & 4 & 174449827 & 174451468\end{array}$

PCDHAC1; PCDHA12;

PCDHA6; PCDHA10; PCDHA4;

PCDHA11; PCDHA8;

PCDHAC1; PCDHA6; PCDHA1;

PCDHA2; PCDHA9; PCDHA1;

PCDHAC1; PCDHA13;

PCDHA5; PCDHA3; PCDHA10

\section{CD81}

HEXA; C15orf34

PCDHAC2; PCDHA7;

PCDHA12; PCDHA6;

PCDHA10; PCDHA4;

PCDHA11; PCDHA8; PCDHA6;

PCDHA1; PCDHA2; PCDHA1;

PCDHA9; PCDHA13; PCDHA5;

PCDHAC1; PCDHA3;

PCDHAC2; PCDHA10

\section{CACNA1C}

C11orf21;TSPAN32

HOXB4

GFI1

APC

ASCL1

HCFC1; TMEM187

CDKL2

CYBA

CTPS2

HAND2; NBLA00301
16

15

10
$1.80 \times 10^{-4}$
$1.99 \times 10^{-4}$
$2.01 \times 10^{-4}$

$2.03 \times 10^{-4}$

$2.09 \times 10^{-4}$

$2.52 \times 10^{-4}$

$2.56 \times 10^{-4}$

$2.70 \times 10^{-4}$

$2.76 \times 10^{-4}$

$2.81 \times 10^{-4}$

$2.94 \times 10^{-4}$

$3.13 \times 10^{-4}$

$3.16 \times 10^{-4}$

$3.34 \times 10^{-4}$ 
Table II. Continued.

\begin{tabular}{lrrrlcr}
\hline Bumps (no.) & Chr & $\begin{array}{c}\text { Start coordinate } \\
\text { of DMR }\end{array}$ & $\begin{array}{c}\text { End coordinate } \\
\text { of DMR }\end{array}$ & Gene(s) & $\begin{array}{c}\text { Number of CpGs } \\
\text { in DMR }\end{array}$ & $\begin{array}{c}\text { DMR } \\
\text { P-value }\end{array}$ \\
\hline 59778 & 2 & 75425832 & 75428132 & TACR1 & 21 & $3.35 \times 10^{-4}$ \\
61130 & 2 & 127413363 & 127414883 & GYPC & 12 & $3.47 \times 10^{-4}$ \\
86294 & 6 & 291687 & 293285 & DUSP22 & 10 & $3.65 \times 10^{-4}$ \\
93730 & 7 & 27280914 & 27282444 & EVX1 & 22 & $3.75 \times 10^{-4}$ \\
15319 & 10 & 118030848 & 118034357 & GFRA1 & 30 & $3.76 \times 10^{-4}$ \\
67499 & 21 & 34442160 & 34443672 & OLIG1 & 14 & $3.93 \times 10^{-4}$ \\
100809 & 8 & 54163622 & 54164442 & OPRK1 & 10 & $4.01 \times 10^{-4}$ \\
62324 & 2 & 177052486 & 177053496 & HOXD1 & 12 & $4.35 \times 10^{-4}$ \\
87226 & 6 & 25652381 & 25652815 & SCGN & 10 & $4.38 \times 10^{-4}$ \\
11057 & 1 & 248020350 & 248021163 & TRIM58 & 10 & $4.42 \times 10^{-4}$ \\
13473 & 10 & 75118103 & 75118887 & TTC18 & 12 & $4.48 \times 10^{-4}$ \\
47489 & 17 & 59476505 & 59478068 & TBX2 & 17 & $4.92 \times 10^{-4}$ \\
97172 & 7 & 130125511 & 130126871 & MEST & 16 & $4.98 \times 10^{-4}$ \\
\hline
\end{tabular}

Chr, chromosome; DMR, differentially methylated region.

indicated that, following the adjustment for age, tumor type, lymph node status and PR expression, RS was an independent predictor for OS in patients with ER-positive BRCA (hazard ratio: 2.551; 95\% confidence interval, 1.048-6.206; $\mathrm{P}=0.039$; Table V).

Additionally, the GSE72251 dataset containing the data of 70 patients with tumor types expressing ER was used for further validation; the median RS among these patients was 0.227 , with a range of 0.053-0.957. As presented in Fig. $3 \mathrm{E}$, patients with $\mathrm{RS} \leq 0.2$ tended to have a better OS times, but statistical significance was not observed (log-rank test, $\mathrm{P}=0.717$ ); however, the $\mathrm{OS}$ times of patients with $\mathrm{RS} \leq 0.5$ were significantly longer compared with that of their counterparts with $\mathrm{RS}>0.5$ (log-rank test, $\mathrm{P}=0.006$; Fig. $3 \mathrm{~F}$ ). IDFS data were available in this dataset and were also analyzed. As presented in Fig. 3G, no significant differences in IDFS were observed between the two groups (patients with BRCA and $\mathrm{RS}>0.2$ compared with those with $\mathrm{RS} \leq 0.2$ ); however, patients assigned a higher RS exhibited a significantly longer IDFS compared with those with a lower RS when the cutoff of RS was set as $0.5(\mathrm{P}=0.009$; Fig. $3 \mathrm{H})$.

Correlation between DNA methylation and mRNA expression in DMRs included in the predictive classifier. Of the 60 DMRs, 63 specific genes were encompassed, and Pearson's correlation coefficients were determined to reveal the effects of epigenetic regulation. The CpG site in one specific DMR exhibiting the strongest correlation with mRNA expression was identified. The majority of the genes (55/63) had a statistically significant correlation between DNA methylation and mRNA expression with a P-value $<0.05$; 17 genes had an r-value $\leq-0.3$ (Table IV). Numerous representative DMRs and their correlation with mRNA expression in specific genes were presented in Fig. 4. Of these genes, EFCAB4B $\left(\mathrm{P}=1.28 \times 10^{-5}\right)$, Schlafen family member 12 (SLFN12; $\left.\mathrm{P}=5.33 \times 10^{-4}\right)$, chromosome 3 open reading frame $18\left(\mathrm{C} 3\right.$ orf $\left.18 ; \mathrm{P}=5.53 \times 10^{-4}\right)$, zinc finger protein $880\left(\mathrm{ZNF} 880 ; \mathrm{P}=9.37 \times 10^{-4}\right)$, dual oxidase 1 (DUOX1; $\mathrm{P}=1.08 \times 10^{-41}$ ) and major histocompatibility complex, class II, DP $\beta 1$ (HLA-DPB1; $\mathrm{P}=2.27 \times 10^{-3}$ ) were hypermethylated in patients in the RTE group, while ELF5 $\left(\mathrm{P}=5.32 \times 10^{-4}\right)$, phospholipase A2 group III (PLA2G3; $\left.\mathrm{P}=1.63 \times 10^{-3}\right)$, metallothionein $1 \mathrm{G}\left(\mathrm{MT} 1 \mathrm{G} ; \mathrm{P}=3.70 \times 10^{-3}\right)$, C-terminal binding protein $1\left(\mathrm{CTBP} 1 ; \mathrm{P}=4.15 \times 10^{-3}\right)$, ALG13 UDP-N-acetylglucosaminyltransferase subunit (ALG13; $\mathrm{P}=2.92 \times 10^{-3}$ ) and RAS protein activator like 1 (RASAL1; $\mathrm{P}=5.93 \times 10^{-3}$ ) were hypomethylated in patients in the RTE group compared with that in the STE group. Among them, ELF5 $\left(r=-0.594, P=2.53 \times 10^{-76}\right)$ exhibited the strongest negative correlation with mRNA expression, followed by PLA2G3 $\left(\mathrm{r}=-0.581, \mathrm{P}=3.43 \times 10^{-72}\right), \mathrm{C} 3$ orf $18\left(\mathrm{r}=-0.567, \mathrm{P}=3.93 \times 10^{-68}\right)$, MT1G $\left(r=-0.536, P=7.32 \times 10^{-60}\right)$, SLFN12 $(r=-0.533$, $\left.\mathrm{P}=3.98 \times 10^{-64}\right)$, ZNF880 ( $\left.\mathrm{r}=-0.464, \mathrm{P}=3.35 \times 10^{-43}\right)$, DUOX1 $\left(\mathrm{r}=-0.456, \mathrm{P}=1.08 \times 10^{-41}\right)$, EFCAB4B $\left(\mathrm{r}=-0.358, \mathrm{P}=3.20 \times 10^{-25}\right)$, HLA-DPB1 $\left(r=-0.300, P=8.83 \times 10^{-18}\right)$, RASAL2 $(r=-0.279$, $\left.\mathrm{P}=1.67 \times 10^{-15}\right)$, CTBP1 $\left(\mathrm{r}=-0.175, \mathrm{P}=7.47 \times 10^{-7}\right)$ and ALG13 $\left(r=-0.122, P=6.13 \times 10^{-4}\right)$.

Effects of the mRNA expression levels of numerous genes on the prognosis of patients with ER-positive BRCA and ET. Considering the association between DNA methylation and mRNA expression levels in the majority of the DMRs included in the prediction model, the effects of the mRNA expression levels of numerous genes on the prognosis of patients with ER-positive BRCA and ET were investigated using independent datasets in the KM Plotter tool. The cutoff value of the mRNA expression level for each gene was set as the median. A number of representative genes are presented in Fig. 5. Patients with higher mRNA expression levels of C3orf18 (log-rank $\mathrm{P}=0.003)$, ZNF880 $(\mathrm{P}=0.035), \mathrm{DUOX} 1 \quad(\mathrm{P}=0.013)$ and HLA-DPB1 $(\mathrm{P}=0.033)$ exhibited significantly longer RFS times compared with those with lower mRNA expression levels. Conversely, patients with lower expression levels of RASAL2 
Table III. Top-ranked 10 biological process terms enriched by genes included in differentially methylated regions determined through the functional enrichment analysis.

\begin{tabular}{|c|c|c|c|}
\hline Description & Gene ratio & Gene ID & P-value \\
\hline $\begin{array}{l}\text { Homophilic cell adhesion via } \\
\text { plasma membrane adhesion } \\
\text { molecules }\end{array}$ & $33 / 446$ & $\begin{array}{l}\text { PCDHA7/PCDHAC1/PCDHA12/PCDHA6/PCDHA10/PCDHA4/ } \\
\text { PCDHA11/PCDHA8/PCDHA1/PCDHA2/PCDHA9/PCDHA13/ } \\
\text { PCDHA5/PCDHA3/PCDHAC2/GYPC/FAT1/SDK1/IGSF9B/ } \\
\text { PCDH8/CDH7/PCDHGA4/PCDHGA6/PCDHGA1/PCDHGA5/ } \\
\text { PCDHGB1/PCDHGB4/PCDHGA3/PCDHGA8/PCDHGA2/ } \\
\text { PCDHGA7/PCDHGB2/PCDHGB3 }\end{array}$ & $9.51 \times 10^{-21}$ \\
\hline $\begin{array}{l}\text { Cell-cell adhesion via } \\
\text { plasma-membrane adhesion } \\
\text { molecules }\end{array}$ & $33 / 446$ & $\begin{array}{l}\text { PCDHA7/PCDHAC1/PCDHA12/PCDHA6/PCDHA10/PCDHA4/ } \\
\text { PCDHA11/PCDHA8/PCDHA1/PCDHA2/PCDHA9/PCDHA13/ } \\
\text { PCDHA5/PCDHA3/PCDHAC2/GYPC/FAT1/SDK1/IGSF9B/ } \\
\text { PCDH8/CDH7/PCDHGA4/PCDHGA6/PCDHGA1/PCDHGA5/ } \\
\text { PCDHGB1/PCDHGB4/PCDHGA3/PCDHGA8/PCDHGA2/ } \\
\text { PCDHGA7/PCDHGB2/PCDHGB3 }\end{array}$ & $1.64 \times 10^{-15}$ \\
\hline Cell fate commitment & $28 / 446$ & $\begin{array}{l}\text { ASCL1/EVX1/OLIG1/TBX2/ELF5/TRIM15/SOX2/NKX6-2/ } \\
\text { NOTCH4/FGFR1/GDF7/FGF10/PROX1/WT1/SOX8/BCL11B/ } \\
\text { EBF2/PITX1/GSX1/GLI3/FGF13/PAX7/NKX2-5/LBX1/GATA3/ } \\
\text { NR2F2/TGFB1I1/GATA2 }\end{array}$ & $4.35 \times 10^{-11}$ \\
\hline Forebrain development & $29 / 446$ & $\begin{array}{l}\text { ASCL1/CXCL12/SOX2/KCNA1/FGFR1/GDF7/FGF10/NPY/ } \\
\text { SRD5A2/PROX1/ALK/BCL11B/PITX1/GSX1/GLI3/FGF13/ } \\
\text { DLX5/AQP1/DAB2IP/EGFR/NR2F2/RARB/TACC2/DUOX2/ } \\
\text { TRAPPC9/GATA2/PITX2/HTR5A/INHBA }\end{array}$ & $9.95 \times 10^{-8}$ \\
\hline Skeletal system development & $33 / 446$ & $\begin{array}{l}\text { HOXC4/HOXC8/HOXB4/HAND2/HOXD1/HOXB5/HOXD9/ } \\
\text { HAPLN3/HOXD4/FGFR1/TBX15/SRD5A2/COL11A2/PITX1/ } \\
\text { HOXC6/HOXC5/GLI3/DLX5/COL1A2/PAX7/GNAS/CDX1/ } \\
\text { TLL1/ALPL/RUNX3/RARB/CDKN1C/PITX2/SHOX2/BARX2/ } \\
\text { BMP8B/COL2A1/MEIS1 }\end{array}$ & $6.24 \times 10^{-7}$ \\
\hline Gland development & $30 / 446$ & $\begin{array}{l}\text { ASCL1/HAND2/TBX2/ELF5/GPX1/HOXD9/SOX2/KALRN/TNF/ } \\
\text { NOTCH4/FGFR1/GDF7/FGF10/PROX1/WT1/BCL11B/PITX1/ } \\
\text { GSX1/GLI3/BSX/LIMS2/NKX2-5/GATA3/EGFR/CDKN1C/ } \\
\text { DUOX2/GATA2/PITX2/UGT1A1/IRS2 }\end{array}$ & $6.45 \times 10^{-7}$ \\
\hline Embryonic organ development & $30 / 446$ & $\begin{array}{l}\text { HOXC4/ASCL2/HOXB4/HAND2/TBX2/HOXB5/HOXD9/TNF/ } \\
\text { HOXD4/FGFR1/CITED1/TBX15/FGF10/VANGL2/PROX1/EN2/ } \\
\text { GLI3/DLX5/GNAS/NKX2-5/LBX1/GATA3/EGFR/NR2F2/RARB/ } \\
\text { CDKN1C/GATA2/PITX2/SHOX2/COL2A1 }\end{array}$ & $7.50 \times 10^{-7}$ \\
\hline Pattern specification process & $30 / 446$ & $\begin{array}{l}\text { HOXC4/HOXC8/HOXB4/ASCL1/HAND2/EVX1/TBX2/HOXB5/ } \\
\text { HOXD9/NKX6-2/HOXD4/FGFR1/CITED1/IRX4/FGF10/ } \\
\text { VANGL2/ GDNF/WT1/HOXC6/HOXC5/GLI3/PAX7/CDX1/ } \\
\text { SYNGAP1/NKX2-5/LBX1/PCDH8/NR2F2/PITX2/BCOR }\end{array}$ & $7.88 \times 10^{-7}$ \\
\hline $\begin{array}{l}\text { Embryonic organ } \\
\text { morphogenesis }\end{array}$ & $23 / 446$ & $\begin{array}{l}\text { HOXC4/HOXB4/HAND2/TBX2/HOXB5/HOXD9/HOXD4/ } \\
\text { FGFR1/TBX15/FGF10/VANGL2/PROX1/GLI3/DLX5/GNAS/ } \\
\text { NKX2-5/LBX1/GATA3/RARB/GATA2/PITX2/SHOX2/COL2A1 }\end{array}$ & $1.86 \times 10^{-6}$ \\
\hline Regulation of hormone levels & $28 / 446$ & $\begin{array}{l}\text { CACNA1C/TACR1/OPRK1/TRH/KALRN/TNF/FGFR1/DUOX1/ } \\
\text { DUOXA1/SRD5A2/SOX8/GALR1/P2RY1/GNAS/KCNS3/ } \\
\text { GATA3/EGFR/DUOX2/DUOXA2/UCN/RAB11FIP3/UGT1A1/ } \\
\text { UGT1A8/UGT1A3/UGT1A9/UGT1A7/IRS2/INHBA }\end{array}$ & $5.88 \times 10^{-5}$ \\
\hline
\end{tabular}

exhibited a significantly longer RFS $(\mathrm{P}=0.006)$ compared with those with increased expression levels. Additionally, separate survival curves associated with EFCAB4B $(\mathrm{P}=0.170)$,
SLFN12 ( $\mathrm{P}=0.063)$, CTBP1 $(\mathrm{P}=0.170)$ and ALG13 $(\mathrm{P}=0.092)$ expression were generated; however, statistical significance was not observed. 
A

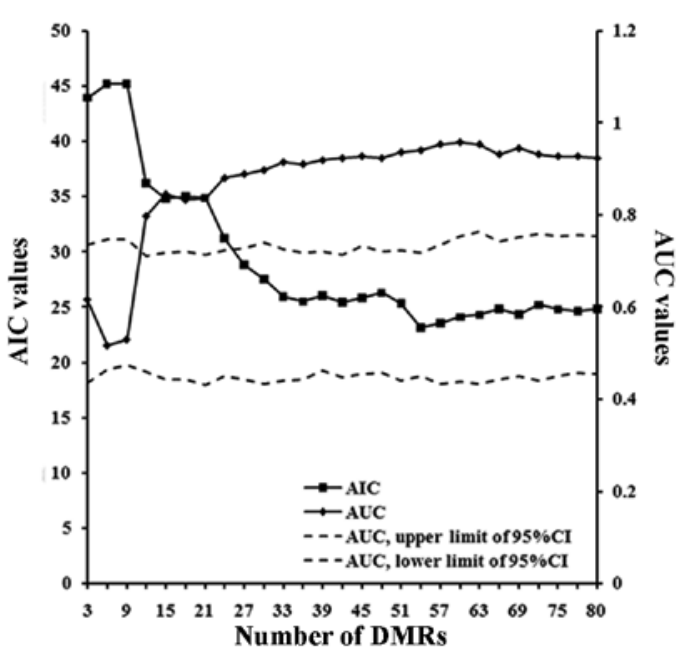

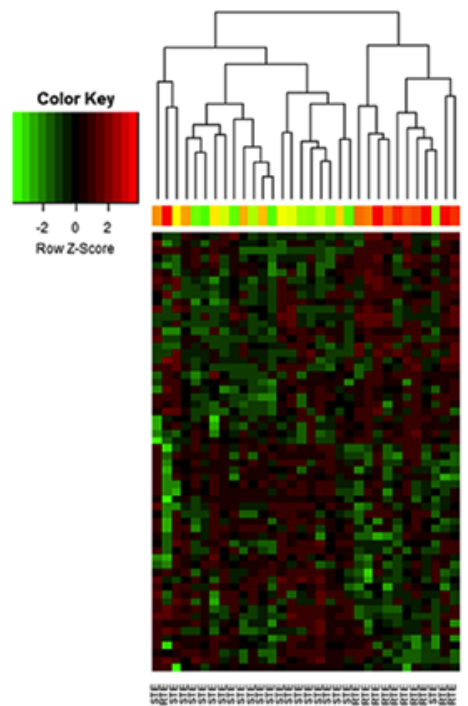

D

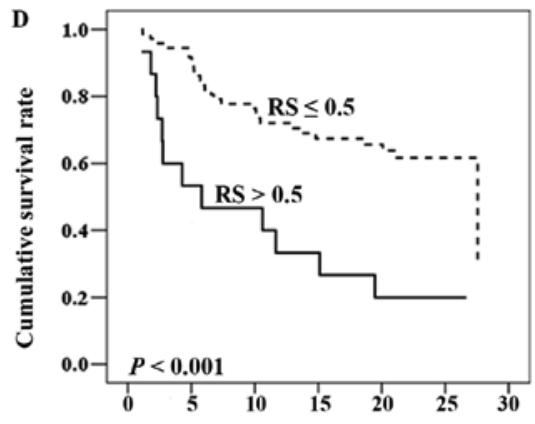

Overall survival (years)

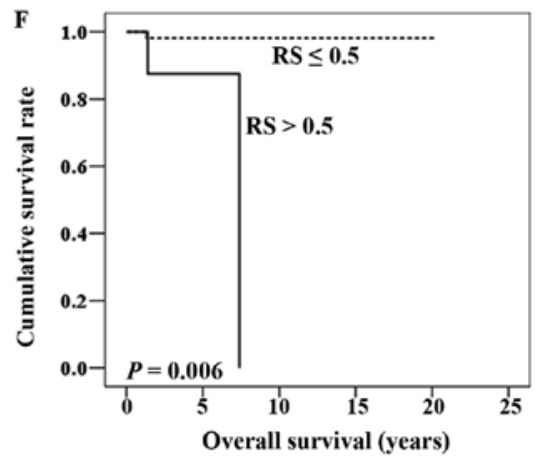

Overall survival (years)

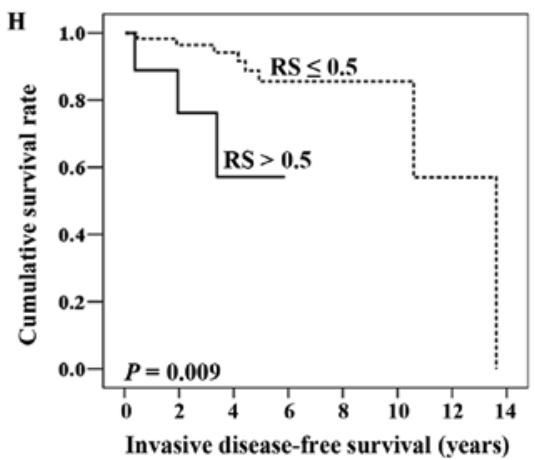

Figure 3. Construction and validation of the predictive classifier. (A) When modeling, 3 DMRs were included into the prediction classifier each time, followed by an assessment of the $m_{R}$ in the STE group and the calculation of the r-value. The effect of the r-values was evaluated using the logistic regression, and AUC and AIC were simultaneously created to assess its diagnostic capacity, the goodness of fit and the simplicity of the classifier. The $95 \%$ CI of the AUC were calculated following 1,000 permutations. The left y-axis represented the AIC values, and the right $y$-axis represented the AUC values. The x-axis indicated the number of DMRs included in the logistic regression. (B) Hierarchical clustering was conducted on the DMRs. Each row of the heat map represented one of the DMRs with each column representing a different sample belonging to the RTE or STE group. RS was retained from each patient in the independent dataset GSE75067 on the basis of the predictive classifier. Kaplan-Meier analyses with log-rank tests were used to assess the effect of RS on OS time. The cutoff value of RS was set to be either (C) 0.2 or (D) 0.5. Similarly, for GSE72251, RS was assigned to each patient and Kaplan-Meier analyses were also used to assess the association between RS and OS, when the cutoff value was set to be (E) 0.2 or (F) 0.5. In addition, survival curves were also created by Kaplan-Meier analyses for invasive disease-free survival time, and the cutoff of RS was set to $(\mathrm{G}) 0.2$ or $(\mathrm{H})$ 0.5. AIC, Akaike information criterion; AUC, area under the curve; CI, confidence interval; RS, risk score; DMR, differentially methylated regions; RTE, resistant to endocrine therapy; STE, sensitive to endocrine therapy; OS, overall survival. 
Table IV. Differentially methylated regions for predicting patients who are resistant to endocrine therapy.

\begin{tabular}{|c|c|c|c|c|c|c|c|}
\hline Bumps (no.) & Gene symbol & r-value ${ }^{a}$ & P-value ${ }^{b}$ & $\begin{array}{l}\text { DNA methylation } \\
\text { (resistant/sensitive } \\
\text { to endocrine therapy) }\end{array}$ & Chr & $\begin{array}{c}\text { No. of } \\
\text { CpG sites }\end{array}$ & P-values ${ }^{c}$ \\
\hline 23474 & EFCAB4B & -0.358 & $3.20 \times 10^{-25}$ & Up & 12 & 12 & $1.28 \times 10^{-5}$ \\
\hline 2013 & PDPN & -0.210 & $2.94 \times 10^{-9}$ & Up & 1 & 17 & $2.35 \times 10^{-5}$ \\
\hline 87359 & $\begin{array}{l}\text { HIST1H4L, } \\
\text { HIST1H3I }\end{array}$ & $\begin{array}{l}-0.233 \\
-0.270\end{array}$ & $\begin{array}{l}3.41 \times 10^{-11} \\
1.26 \times 10^{-14}\end{array}$ & Up & 6 & 16 & $8.00 \times 10^{-5}$ \\
\hline 29316 & EPSTI1 & -0.581 & $2.89 \times 10^{-72}$ & Up & 13 & 14 & $9.85 \times 10^{-5}$ \\
\hline 23388 & CACNA1C & 0.305 & $1.86 \times 10^{-18}$ & Up & 12 & 14 & $2.03 \times 10^{-4}$ \\
\hline 83500 & APC & 0.075 & $3.57 \times 10^{-2}$ & Up & 5 & 15 & $2.70 \times 10^{-4}$ \\
\hline 109271 & $\begin{array}{l}\text { HCFC1, } \\
\text { TMEM187 }\end{array}$ & $\begin{array}{c}0.072 \\
-0.076\end{array}$ & $\begin{array}{l}4.37 \times 10^{-2}, \\
3.27 \times 10^{-2}\end{array}$ & Down & $X$ & 19 & $2.81 \times 10^{-4}$ \\
\hline 87226 & SCGN & -0.194 & $3.83 \times 10^{-8}$ & Down & 6 & 10 & $4.38 \times 10^{-4}$ \\
\hline 11057 & TRIM58 & -0.619 & $1.39 \times 10^{-84}$ & Down & 1 & 10 & $4.42 \times 10^{-4}$ \\
\hline 93160 & $\begin{array}{l}\text { MIR589, } \\
\text { FBXL18 }\end{array}$ &,--0.255 &,$- 4.23 \times 10^{-13}$ & Down & 7 & 12 & $5.07 \times 10^{-4}$ \\
\hline 18397 & ELF5 & -0.594 & $2.53 \times 10^{-76}$ & Down & 11 & 13 & $5.32 \times 10^{-4}$ \\
\hline 45490 & SLFN12 & -0.553 & $3.98 \times 10^{-64}$ & $\mathrm{Up}$ & 17 & 9 & $5.33 \times 10^{-4}$ \\
\hline 72514 & C3orf18 & -0.567 & $3.93 \times 10^{-68}$ & Up & 3 & 7 & $5.53 \times 10^{-4}$ \\
\hline 86221 & SCGB3A1 & -0.309 & $7.02 \times 10^{-19}$ & Up & 5 & 14 & $5.56 \times 10^{-4}$ \\
\hline 19965 & SIPA1 & -0.260 & $1.13 \times 10^{-13}$ & Up & 11 & 12 & $6.43 \times 10^{-4}$ \\
\hline 53071 & ACP5 & -0.222 & $3.18 \times 10^{-10}$ & $\mathrm{Up}$ & 19 & 11 & $6.58 \times 10^{-4}$ \\
\hline 67311 & MIR155HG & -0.424 & $1.01 \times 10^{-35}$ & $\mathrm{Up}$ & 21 & 7 & $7.44 \times 10^{-4}$ \\
\hline 16291 & NKX6-2 & -0.048 & $1.76 \times 10^{-1}$ & Down & 10 & 12 & $8.42 \times 10^{-4}$ \\
\hline 56468 & ZNF880 & -0.464 & $3.35 \times 10^{-43}$ & $\mathrm{Up}$ & 19 & 9 & $9.37 \times 10^{-4}$ \\
\hline 78770 & IGFBP7 & 0.084 & $1.82 \times 10^{-2}$ & Down & 4 & 8 & $1.01 \times 10^{-3}$ \\
\hline 12633 & ALOX5 & -0.189 & $8.55 \times 10^{-8}$ & $\mathrm{Up}$ & 10 & 7 & $1.06 \times 10^{-3}$ \\
\hline 20753 & PHOX2A & -0.225 & $1.79 \times 10^{-10}$ & Down & 11 & 7 & $1.09 \times 10^{-3}$ \\
\hline 33797 & PPP2R5C & 0.068 & $5.51 \times 10^{-2}$ & Up & 14 & 5 & $1.13 \times 10^{-3}$ \\
\hline 51880 & NFIC & 0.140 & $8.11 \times 10^{-5}$ & Up & 19 & 5 & $1.17 \times 10^{-3}$ \\
\hline 87280 & HIST1H4F & -0.228 & $1.14 \times 10^{-10}$ & Up & 6 & 7 & $1.25 \times 10^{-3}$ \\
\hline 94632 & IKZF1 & -0.265 & $4.47 \times 10^{-14}$ & Down & 7 & 6 & $1.25 \times 10^{-3}$ \\
\hline 67598 & CBR1 & -0.621 & $3.20 \times 10^{-85}$ & $\mathrm{Up}$ & 21 & 6 & $1.27 \times 10^{-3}$ \\
\hline 102219 & ZNF572 & -0.645 & $1.22 \times 10^{-93}$ & Up & 8 & 8 & $1.30 \times 10^{-3}$ \\
\hline 35402 & $\begin{array}{l}\text { DUOX1, } \\
\text { DUOXA1 }\end{array}$ & $\begin{array}{l}-0.456 \\
-0.485\end{array}$ & $\begin{array}{l}1.08 \times 10^{-41} \\
1.03 \times 10^{-47}\end{array}$ & Up & 15 & 9 & $1.36 \times 10^{-3}$ \\
\hline 108507 & CHRDL1 & 0.120 & $7.29 \times 10^{-4}$ & Down & $X$ & 9 & $1.61 \times 10^{-3}$ \\
\hline 69212 & PLA2G3 & -0.581 & $3.43 \times 10^{-72}$ & Down & 22 & 6 & $1.63 \times 10^{-3}$ \\
\hline 23113 & GLB1L3 & -0.175 & $8.25 \times 10^{-7}$ & Down & 11 & 7 & $1.89 \times 10^{-3}$ \\
\hline 98905 & VIPR2 & -0.433 & $2.76 \times 10^{-37}$ & Down & 7 & 6 & $1.92 \times 10^{-3}$ \\
\hline 28896 & GSX1 & -0.094 & $8.09 \times 10^{-3}$ & Down & 13 & 9 & $1.98 \times 10^{-3}$ \\
\hline 88104 & HLA-DPB 1 & -0.300 & $8.83 \times 10^{-18}$ & Up & 6 & 9 & $2.26 \times 10^{-3}$ \\
\hline 86545 & CDYL & -0.073 & $4.05 \times 10^{-2}$ & $\mathrm{Up}$ & 6 & 6 & $2.30 \times 10^{-3}$ \\
\hline 11209 & DIP2C & -0.194 & $3.95 \times 10^{-8}$ & Down & 10 & 15 & $2.50 \times 10^{-3}$ \\
\hline 97788 & FAM115A & 0.061 & $8.98 \times 10^{-2}$ & $\mathrm{Up}$ & 7 & 4 & $2.54 \times 10^{-3}$ \\
\hline 84265 & LOC389333 & -0.165 & $3.14 \times 10^{-6}$ & $\mathrm{Up}$ & 5 & 8 & $2.58 \times 10^{-3}$ \\
\hline 17233 & TRIM68 & -0.573 & $5.39 \times 10^{-70}$ & Up & 11 & 8 & $2.63 \times 10^{-3}$ \\
\hline 57826 & KCNS3 & -0.227 & $1.13 \times 10^{-10}$ & Up & 2 & 8 & $2.65 \times 10^{-3}$ \\
\hline 30133 & DOCK9 & -0.119 & $7.89 \times 10^{-4}$ & Down & 13 & 6 & $2.74 \times 10^{-3}$ \\
\hline 108522 & ALG13 & -0.122 & $6.13 \times 10^{-4}$ & Down & $\mathrm{X}$ & 5 & $2.92 \times 10^{-3}$ \\
\hline 7843 & SLAMF1 & -0.270 & $1.33 \times 10^{-14}$ & Up & 1 & 6 & $3.20 \times 10^{-3}$ \\
\hline 99079 & ARHGEF10 & -0.030 & $4.00 \times 10^{-1}$ & Down & 8 & 4 & $3.47 \times 10^{-3}$ \\
\hline 40848 & MT1G & -0.536 & $7.32 \times 10^{-60}$ & Down & 16 & 6 & $3.70 \times 10^{-3}$ \\
\hline
\end{tabular}


Table IV. Continued.

\begin{tabular}{|c|c|c|c|c|c|c|c|}
\hline Bumps (no.) & Gene symbol & r-value ${ }^{a}$ & P-value ${ }^{b}$ & $\begin{array}{l}\text { DNA methylation } \\
\text { (resistant/sensitive } \\
\text { to endocrine therapy) }\end{array}$ & Chr & $\begin{array}{c}\text { No. of } \\
\text { CpG sites }\end{array}$ & P-values ${ }^{c}$ \\
\hline 26270 & LIN7A & -0.291 & $7.61 \times 10^{-17}$ & Up & 12 & 4 & $4.08 \times 10^{-3}$ \\
\hline 57453 & TTC15 & 0.195 & $3.45 \times 10^{-8}$ & Down & 2 & 5 & $4.13 \times 10^{-3}$ \\
\hline 77073 & СТВP1 & -0.175 & $7.47 \times 10^{-7}$ & Down & 4 & 6 & $4.15 \times 10^{-3}$ \\
\hline 42328 & FBXO31 & -0.075 & $3.59 \times 10^{-2}$ & $\mathrm{Up}$ & 16 & 3 & $4.28 \times 10^{-3}$ \\
\hline 85239 & EBF1 & 0.035 & $3.28 \times 10^{-1}$ & Down & 5 & 4 & $4.31 \times 10^{-3}$ \\
\hline 19658 & FERMT3 & 0.102 & $4.24 \times 10^{-3}$ & Down & 11 & 4 & $4.32 \times 10^{-3}$ \\
\hline 7847 & CD48 & -0.143 & $5.38 \times 10^{-5}$ & Up & 1 & 4 & $4.56 \times 10^{-3}$ \\
\hline 102571 & TRAPPC9 & 0.060 & $9.15 \times 10^{-2}$ & Down & 8 & 3 & $5.43 \times 10^{-3}$ \\
\hline 49506 & HEXDC & 0.078 & $2.90 \times 10^{-2}$ & Down & 17 & 3 & $5.80 \times 10^{-3}$ \\
\hline 81036 & ACSL1 & 0.060 & $9.37 \times 10^{-2}$ & Down & 4 & 3 & $5.89 \times 10^{-3}$ \\
\hline 8503 & RASAL2 & -0.279 & $1.67 \times 10^{-15}$ & Down & 1 & 3 & $5.93 \times 10^{-3}$ \\
\hline 40647 & ZNF423 & 0.384 & $4.02 \times 10^{-29}$ & $\mathrm{Up}$ & 16 & 4 & $6.19 \times 10^{-3}$ \\
\hline 393 & PRKCZ & -0.065 & $6.77 \times 10^{-2}$ & Down & 1 & 3 & $6.31 \times 10^{-3}$ \\
\hline 11176 & DIP2C & -0.194 & $3.95 \times 10^{-8}$ & Down & 10 & 4 & $6.67 \times 10^{-3}$ \\
\hline
\end{tabular}

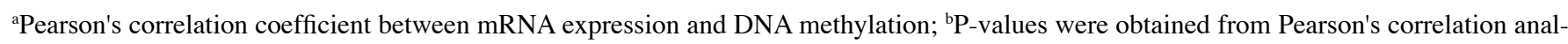
yses; ${ }^{\mathrm{C}} \mathrm{P}$-values represented the statistical significance of differentially methylated regions on identifying patients with estrogen receptor-positive breast cancer sensitive to endocrine therapy; Chr, chromosome.

Table V. Univariate and multivariate Cox regressions in the dataset GSE75067.

\begin{tabular}{lrrrrrr}
\hline & \multicolumn{2}{c}{ Univariate } & & & \multicolumn{2}{c}{ Multivariate } \\
\cline { 2 - 3 } Clinical features & HR $(95 \% \mathrm{CI})$ & P-value & & HR (95\%CI) & P-value \\
\hline Age (years, $>50 / \leq 50)$ & $1.286(0.677,2.442)$ & 0.442 & & $1.688(0.800,3.563)$ & 0.170 \\
Tumor types (non-ductal/ductal) & $0.613(0.290,1.294)$ & 0.199 & & $0.528(0.224,1.245)$ & 0.145 \\
Lymph node status (positive/negative) & $4.199(2.096,8.411)$ & $<0.001$ & & $5.319(2.440,11.596)$ & $<0.001$ \\
Progesterone receptor expression (positive/negative) & $0.472(0.215,1.036)$ & 0.061 & & $1.282(0.429,3.835)$ & 0.656 \\
Risk Score $(>0.5 / \leq 0.5)$ & $3.463(1.742,6.887)$ & $<0.001$ & & $2.551(1.048,6.206)$ & 0.039 \\
\hline
\end{tabular}

HR, hazard ratio; CI, confidence interval.

\section{Discussion}

Previous studies have indicated that dysregulated DNA methylation is associated with carcinogenesis and therapeutic effectiveness $(16,17,42)$. In the present study, DMRs were identified via the bumphunting analysis, followed by the building of a predictive classifier to identify ET-responsive patients with ER-positive BRCA. The RS was then calculated, which served as an indicator to classify patients with ER-positive BRCA into two groups with distinct survival outcomes in two additional independent datasets.

Functional enrichment analyses demonstrated that genes with DMRs associated with ET sensitivity were associated organ morphogenesis and development and cell-cell adhesion. The present study mainly reported on two groups of genes, namely the PCDH family and homeobox genes. PCDHs, as part of the cadherin superfamily, were originally identified in the rat brain via polymerase chain reaction analysis and were associated with certain types of neurological disease $(43,44)$. Previously, aberrant PCDH expression was observed in a variety of human malignant tumor types, potentially due to post-translational regulatory mechanisms, including DNA methylation (45). In the present study, it was reported that the methylation status of numerous PCDHs, including PCDHA4, PCDHA7, PCDHA10, PCDH8 and PCDHGA1 may be associated with the resistance to ET. In addition, the tumor suppressor and oncogenic functions of PCDHs have been reported in BRCA $(46,47)$. The effects of certain PCDHs, including PCDH10, have been associated with fulvestrant resistance in BRCA (48). The function of PCDHs is associated with numerous signaling pathways, including the $\mathrm{Wnt} / \beta$-catenin (49) and receptor tyrosine kinase (50) pathways, which have been proposed to be associated with tamoxifen resistance. The results of 

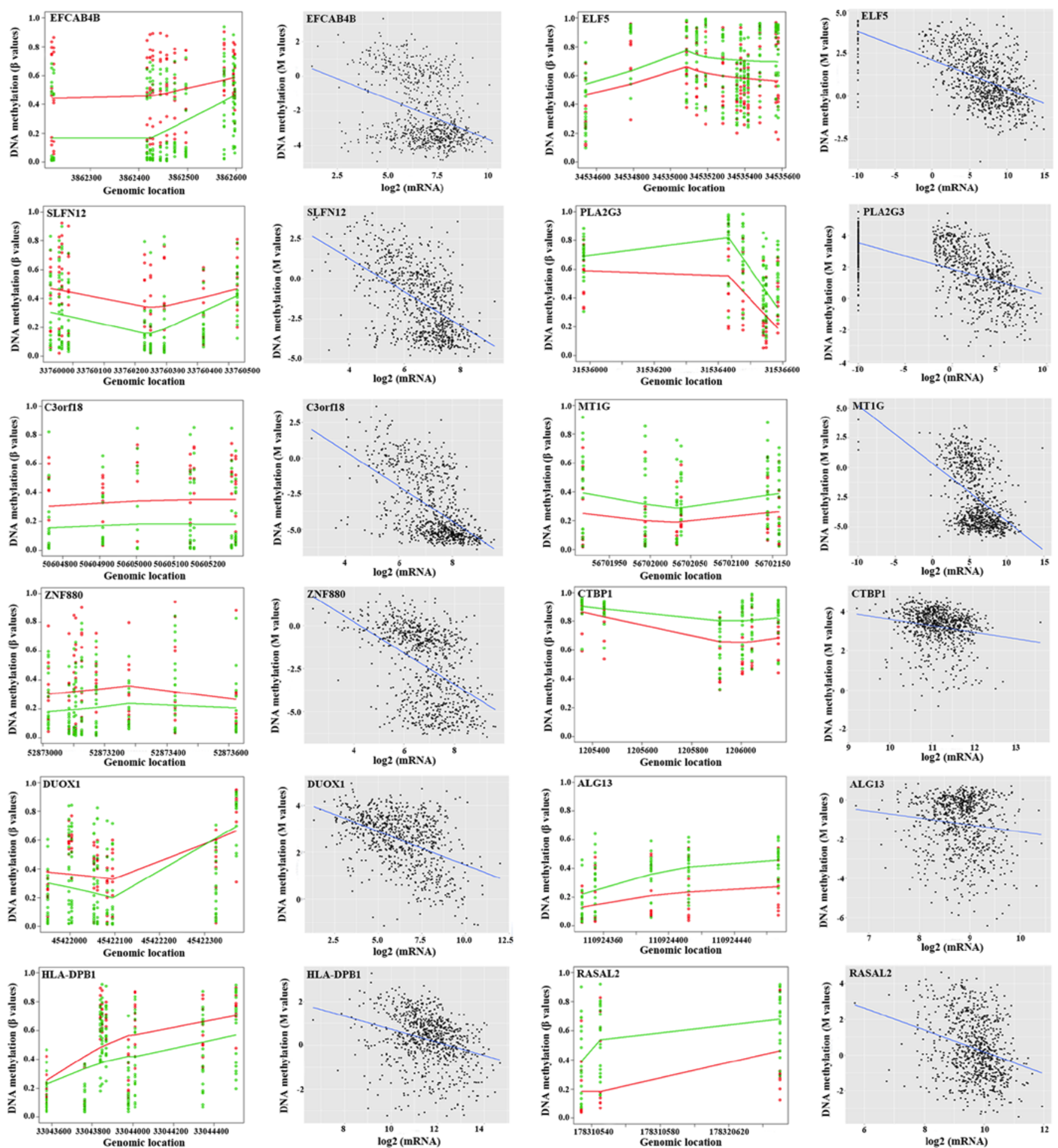

Figure 4. DMRs of a number of specific genes between the RTE and STE groups and their association with mRNA expression levels. Left: The points exhibited methylation measurements against genomic location. A total of 11 RTE and 21 STE samples were presented and represented by red points and green points, respectively, at each genomic location. The curves represent the smooth estimate of the population-level methylation profiles for RTE (red) and STE (green) samples. Right: Methylation measurements (M values) of a number of DMRs were plotted against the log-transformed mRNA expression. Each point represented an individual sample from 787 tumor/adjacent tissues measured using DNA methylation and RNA sequencing data. The specific gene covering the DMRs is presented in the top left. DMR, differentially methylated regions; RTE, resistant to endocrine therapy; STE, sensitive to endocrine therapy; EFCAB4B, calcium release activated channel regulator 2A; ELF5, E74 like ETS transcription factor 5; SLFN12, Schlafen family member 12; PLA2G3, phospholipase A2 group III; C3orf18, chromosome 3 open reading frame 18; MT1G, metallothionein 1G; ZNF880, zinc finger protein 880; CTBP1, C-terminal binding protein 1; DUOX1, dual oxidase 1; ALG13, ALG13 UDP-N-acetylglucosaminyltransferase subunit; HLA-DPB1, major histocompatibility complex, class II, DP $\beta 1$; RASAL2, RAS protein activator like 2.

the present study suggested a potential association between PCDHs and resistance to ET; however, further investigation is required.
Additionally, the HOX genes encode a family of highly conserved homeodomain-containing transcription factors that serve crucial functions during embryogenesis (51). In BRCA, 

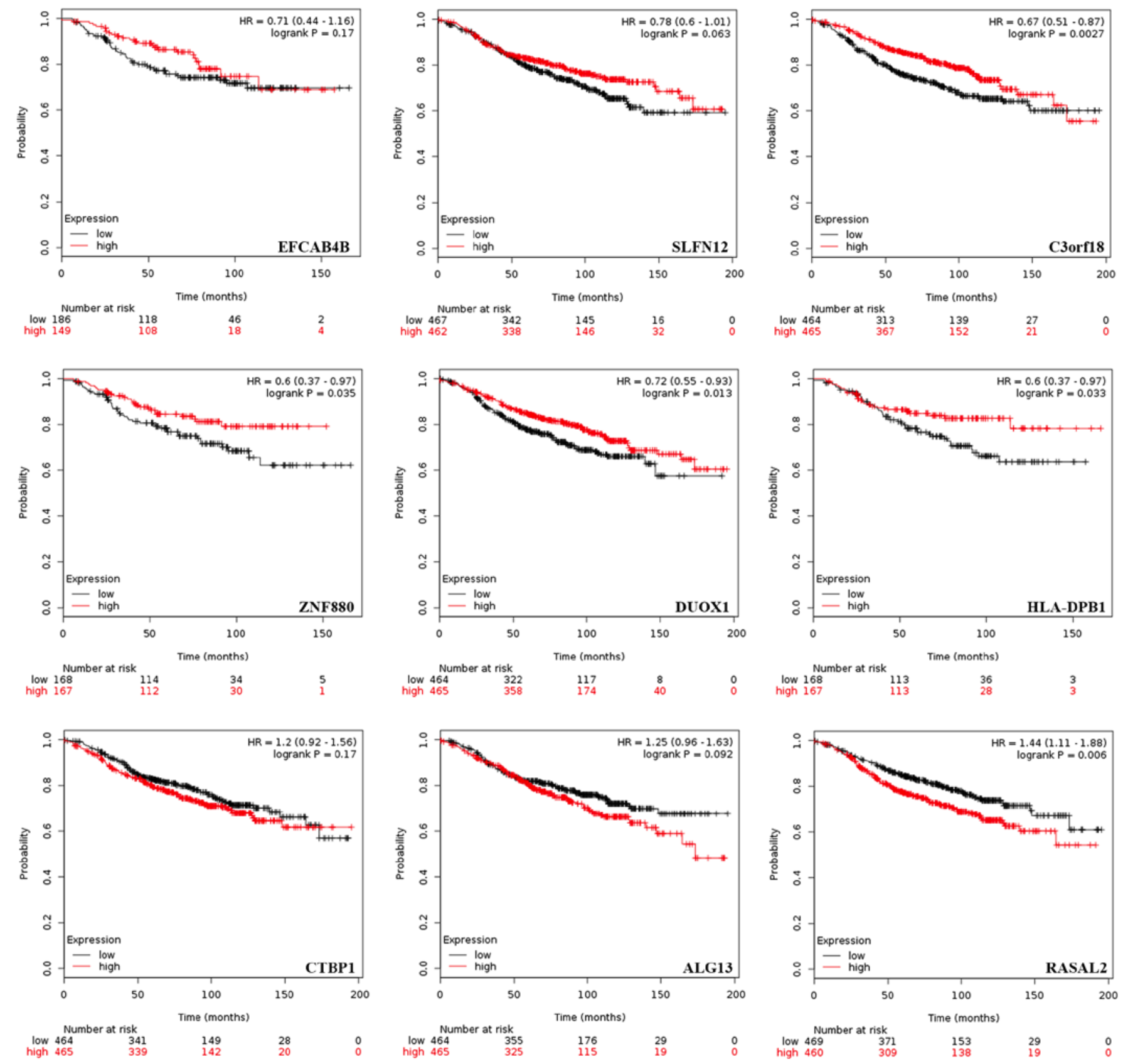

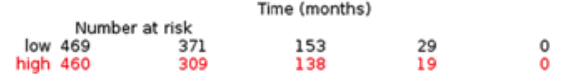

Figure 5. Prognostic significance of mRNA expression of a number of specific genes in estrogen receptor-positive patients with BRCA receiving ET. Effect of mRNA expression on the relapse-free survival time of patients with BRCA receiving ET was assessed using the Kaplan Meier plotter. P-values were obtained from Kaplan Meier analysis with a log-rank test. ET, endocrine therapy; BRCA, breast cancer; EFCAB4B, calcium release activated channel regulator 2A; SLFN12, Schlafen family member 12; C3orf18, chromosome 3 open reading frame 18; ZNF880, zinc finger protein 880; DUOX1, dual oxidase 1; HLA-DPB1, major histocompatibility complex, class II, DP $\beta 1$; CTBP1, C-terminal binding protein 1; ALG13, ALG13 UDP-N-acetylglucosaminyltransferase subunit; RASAL2, RAS protein activator like 2.

the expression of numerous HOX genes has been reported to be up- or downregulated, which may be associated with carcinogenesis, metastasis and tamoxifen resistance $(52,53)$. It was proposed that HOX genes contribute to a major part of DNA methylation profiles in BRCA subtypes (54). In the present study, the methylation patterns of numerous HOX genes, including HOXB4, HOXB5, HOXC4, HOXC8, HOXD1 and HOXD4, were observed to be associated with resistance to ET.

DNA methylation of gene promoters may downregulate transcriptional expression, affecting tumorigenesis or the progression of tumor types (52). Therefore, gene promoters have become the focus of research to investigate DNA methylation. Li et al (55) reported that 3.3\% inter-tumor gene expression maybe attributed to DNA methylation in gene promoters. The present study revealed that the locations of DMRs were primarily in the gene promoter, namely TSS200 and TSS1500; however, other regions, including the gene body, additionally exhibited a large proportion of methylation, which indicated that other regions containing $\mathrm{CpG}$ sites may regulate gene expression, contributing to ET resistance. Li et al (55) revealed that in addition to the gene promoter, other regions may substantially affect inter-tumor gene 
expression. For instance, enhancer methylation was associated with $4.0 \%$ of inter-tumor gene expression variation (56). Compared with a single $\mathrm{CpG}$ site, the varied methylation of genomic regions containing a number of $\mathrm{CpG}$ sites was more stable. Integrating the bumphunting method and logistic regression, 60 DMRs were reported to have the potential to identify patients with ER-positive BRCA and ET resistance. Due to the inadequate treatment information of the data from TCGA and the stringent criteria set, sample sizes in the present study were limited. Therefore, 11 patients with BRCA possessing a DFS $\leq 30$ months were regarded as exhibiting ET resistance, while 21 patients exhibiting a DFS $>100$ months were regarded as sensitive to ET $(57,58)$. The limited sample sizes may reduce the comparative power of the identification of DMRs. Therefore, multiple test adjustment was not applied to retain potentially genuine biomarkers. Furthermore, the GSE75067 and GSE72251 datasets lacking treatment information were included to externally validate the model proposed in the present study. The survival curves, particularly when the cutoff value of RS was set as 0.5 , demonstrated notable curve separation in patients with ER-positive BRCA. These survival analyses indicated the potential application of RS in the prediction of the prognosis of patients with ER-positive BRCA and suggested its potential for identifying patients resistant to ET; however, cohorts with a large sample size are required to further support this predictive classifier.

Pearson's correlation analyses revealed that the majority of DMRs (46/60) in the predictive model of the present study exhibited a negative correlation with the transcript expression. Numerous genes in this model, including ELF5 (59), CTBP1 (60) and zinc finger protein 423 (ZNF423) (61), have previously been reported to be involved in anti-estrogen resistance. Elevated expression levels of ELF5 were detected in luminal BRCA cells that had acquired resistance to tamoxifen (59). In addition, ELF5 may be a key transcriptional determinant of BRCA molecular subtypes by suppressing estrogen sensitivity in luminal BRCA cells (59). Furthermore, as a corepressor, CTBP1 was reported to be associated with the silencing of ubiquitin-conjugating enzyme E2 D1 and simultaneously elevated cyclin D1 expression levels, which may underlie the mechanism of acquired resistance to 4-hydroxytamoxifen (60). It was demonstrated that ZNF423 may be an estrogen-inducible BRCA1 transcription factor, and may contribute to variations in selective ER modulators in the prevention of BRCA (61). Additionally, a number of other genes, namely APC regulator of WNT signaling pathway, PDPN, EPSTI1, SCGB3A1, signal-induced proliferation-associated 1 , acid phosphatase 5 , tartrate resistant, MIR155 host gene, insulin like growth factor binding protein 7, arachidonate 5-lipoxygenase, protein phosphatase 2 regulatory subunit B' $\gamma$, nuclear factor I C, IKAROS family zinc finger 1, carbonyl reductase 1, DUOXA1, chordin like 1, disco interacting protein 2 homolog $\mathrm{C}$, signaling lymphocytic activation molecule family member 1 , Rho guanine nucleotide exchange factor $10, \mathrm{MT} 1 \mathrm{G}$, lin-7 homolog A, crumbs cell polarity complex component, F-box protein 31, EBF transcription factor 1, trafficking protein particle complex 9, acyl-CoA synthetase long chain family member 1, RASAL2, ZNF423, protein kinase CZ, PLA2G3 and ALG13 have been reported to be involved in the development of cancer (62-65), including
BRCA; however, their association with ET resistance remains unknown. For instance, previous studies have identified the increased methylation of SCGB3A1 in metastases compared with that in primary breast tumor types $(62,63)$. In non-invasive MCF7 cells, DUOXA1 expression was upregulated compared with that in highly metastatic cells; DUOXA1 overexpression sensitized cells to doxorubicin (64). In the present study, the increased DNA methylation of SCGB3A1 and DUOXA1 were observed in the RTE group, indicating their potential function in resistance to anti-estrogenic treatment. Additionally, a significant difference in the methylation frequencies and expression levels of MT1G was reported between BRCA subtypes (65). MT1G hypomethylation in patients who were resistant to ET was detected in the present study, indicating its association with antiestrogen therapy. The present study also reported numerous genes that have been rarely investigated in cancer research, including EFCAB4B. EFCAB4B is a $\mathrm{Ca}^{2+}$-binding protein that serves a key function in store-operated calcium entry in T-cells (66). A previous study demonstrated EFCAB4B hypermethylation in a twin with rheumatoid arthritis compared with their healthy co-twin (67). The results of the present study indicate a putative function of EFCAB4B in ET or potential immune/inflammatory alterations in the tumor microenvironment; however, further investigation is required.

Generally, the targeting of numerous genes has been reported to be superior to targeting an individual target, and DNA methylation patterns have become a promising diagnostic tool in addition to gene transcripts in BRCA. In the present study, a number of DMRs were detected between patients with ET resistance and those sensitive to ET; DMRs were used to build a predictive classifier. Furthermore, an RS was generated based on the classifier, which may determine the distinct outcomes of patients with ER-positive BRCA, suggesting a beneficial function in the identification of patients who are resistant to ET. Additionally, a potential function underlying the development of BRCA and resistance to ET was indicated for a number of genes (EFCAB4B and SLFN12); however, further investigation using a larger cohort is required. The present study primarily proposed a useful tool for assessing patient responses to ET and a number of potential therapeutic targets to promote the sensitivity of patients to ET with ER-positive BRCA.

\section{Acknowledgements}

Not applicable.

\section{Funding}

The present study was supported by the Medical Scientific Research Foundation of Guangdong Province, China (grant no. A2017425), the Youth Research Grant from Shantou University Medical College Cancer Hospital [grant no. 2018A001, (2018)36] and the Key Project of Science and Technology of Shantou [grant no. (2018)37] to Mrs. Fan Zhang; and National Natural Science Foundation of China (grant nos. 81872147 and 81572588), the Running Open Grant of Guangdong Provincial Key Laboratory for Breast Cancer Diagnosis and Treatment (grant no. 2017B030314116), 
and Guangdong Provincial Special Fund of Science Innovation Stratege (grant no. 180918104960680) to Professor Yukun Cui.

\section{Availability of data and materials}

The datasets analyzed during the present study are available from The Cancer Genome Atlas (https://portal.gdc.cancer. gov/) and the Gene Expression Omnibus (https://www.ncbi. nlm.nih.gov/gds/) databases.

\section{Authors' contributions}

FZ and YC participated in the conception and design of the study. FZ downloaded, analyzed the data and drafted the manuscript. YC revised the manuscript prior to submission. Both authors have read and approved the final version of the manuscript.

\section{Ethics approval and consent to participate}

Not applicable.

\section{Patient consent for publication}

Not applicable.

\section{Competing interests}

The authors declare that they have no competing interests.

\section{References}

1. Jiang $\mathrm{X}$, Tang $\mathrm{H}$ and Chen $\mathrm{T}$ : Epidemiology of gynecologic cancers in China. J Gynecol Oncol 29: e7, 2018.

2. Campbell LL and Polyak K: Breast tumor heterogeneity: Cancer stem cells or clonal evolution? Cell Cycle 6: 2332-2338, 2007.

3. Nicolini A, Ferrari P and Duffy MJ: Prognostic and predictive biomarkers in breast cancer: Past, present and future. Semin Cancer Biol 52: 56-73, 2018.

4. Hammond ME, Hayes DF, Dowsett M, Allred DC, Hagerty KL, Badve S, Fitzgibbons PL, Francis G, Goldstein NS, Hayes M, et al: American Society of Clinical Oncology/College of American Pathologists guideline recommendations for immunohistochemical testing of estrogen and progesterone receptors in breast cancer (unabridged version). Arch Pathol Lab Med 134: e48-e72, 2010.

5. Mendes TF, Kluskens LD and Rodrigues LR: Triple negative breast cancer: Nanosolutions for a big challenge. Adv Sci (Weinh) 2: 1500053, 2015.

6. Badia E, Oliva J, Balaguer P and Cavaillès V: Tamoxifen resistance and epigenetic modifications in breast cancer cell lines. Curr Med Chem 14: 3035-3045, 2007.

7. Abdel-Hafiz HA: Epigenetic mechanisms of tamoxifen resistance in luminal breast cancer. Diseases 5: pii: E16, 2017.

8. Harbeck $\mathrm{N}$ and Rody A: Lost in translation? Estrogen receptor status and endocrine responsiveness in breast cancer. J Clin Oncol 30: 686-689, 2012.

9. Gururaj AE, Rayala SK, Vadlamudi RK and Kumar R: Novel mechanisms of resistance to endocrine therapy: Genomic and nongenomic considerations. Clin Cancer Res 12: 1001s-1007s, 2006.

10. Ali S and Coombes RC: Endocrine-responsive breast cancer and strategies for combating resistance. Nat Rev Cancer 2: 101-112, 2002.

11. Smith IE, Walsh G, Skene A, Llombart A, Mayordomo JI, Detre S, Salter J, Clark E, Magill P and Dowsett M: A phase II placebo-controlled trial of neoadjuvant anastrozole alone or with gefitinib in early breast cancer. J Clin Oncol 25: 3816-3822, 2007.
12. Johnston SR, Martin LA, Leary A, Head J and Dowsett M: Clinical strategies for rationale combinations of aromatase inhibitors with novel therapies for breast cancer. J Steroid Biochem Mol Biol 106: 180-186, 2007

13. Paik S, Shak S, Tang G, Kim C, Baker J, Cronin M, Baehner FL, Walker MG, Watson D, Park T, et al: A multigene assay to predict recurrence of tamoxifen-treated, node-negative breast cancer. N Engl J Med 351: 2817-2826, 2004.

14. Cardoso F, van't Veer LJ, Bogaerts J, Slaets L, Viale G, Delaloge S, Pierga JY, Brain E, Causeret S, DeLorenzi M, et al: 70-Gene signature as an aid to treatment decisions in early-stage breast cancer. N Engl J Med 375: 717-729, 2016.

15. Stone A, Valdes-Mora F and Clark SJ: Exploring and exploiting the aberrant DNA methylation profile of endocrine-resistant breast cancer. Epigenomics 5: 595-598, 2013.

16. Jones PA and Baylin SB: The epigenomics of cancer. Cell 128: 683-692, 2007.

17. Glasspool RM, Teodoridis JM and Brown R: Epigenetics as a mechanism driving polygenic clinical drug resistance. $\mathrm{Br} \mathrm{J}$ Cancer 94: 1087-1092, 2006.

18. Ward AK, Mellor P, Smith SE, Kendall S, Just NA, Vizeacoumar FS, Sarker S, Phillips Z, Alvi R, Saxena A, et al: Epigenetic silencing of CREB3L1 by DNA methylation is associated with high-grade metastatic breast cancers with poor prognosis and is prevalent in triple negative breast cancers. Breast Cancer Res 18: 12, 2016.

19. Lubecka K, Kurzava L, Flower K, Buvala H, Zhang H, Teegarden D, Camarillo I, Suderman M, Kuang S, Andrisani O, et al: Stilbenoids remodel the DNA methylation patterns in breast cancer cells and inhibit oncogenic NOTCH signaling through epigenetic regulation of MAML2 transcriptional activity. Carcinogenesis 37: 656-668, 2016.

20. Looi ML, Zakaria H, Osman J and Jamal R: Quantity and quality assessment of DNA extracted from saliva and blood. Clin Lab 58: 307-312, 2012.

21. Bediaga NG, Acha-Sagredo A, Guerra I, Viguri A, Albaina C Ruiz Diaz I, Rezola R, Alberdi MJ, Dopazo J, Montaner D, et al: DNA methylation epigenotypes in breast cancer molecular subtypes. Breast Cancer Res 12: R77, 2010.

22. Feng W, Shen L, Wen S, Rosen DG, Jelinek J, Hu X, Huan S, Huang M, Liu J, Sahin AA, et al: Correlation between CpG methylation profiles and hormone receptor status in breast cancers. Breast Cancer Res 9: R57, 2007.

23. Holm K, Hegardt C, Staaf J, Vallon-Christersson J, Jonsson G, Olsson H, Borg A and Ringnér M: Molecular subtypes of breast cancer are associated with characteristic DNA methylation patterns. Breast Cancer Res 12: R36, 2010.

24. Stone A, Valdés-Mora F, Gee JM, Farrow L, McClelland RA, Fiegl H, Dutkowski C, McCloy RA, Sutherland RL, Musgrove EA and Nicholson RI: Tamoxifen-induced epigenetic silencing of oestrogen-regulated genes in anti-hormone resistant breast cancer. PLoS One 7: e40466, 2012.

25. Magnani L, Stoeck A, Zhang X, Lanczky A, Mirabella AC, Wang TL, Gyorffy B and Lupien M: Genome-wide reprogramming of the chromatin landscape underlies endocrine therapy resistance in breast cancer. Proc Natl Acad Sci USA 110: E1490-E1499, 2013.

26. Aran D and Hellman A: DNA methylation of transcriptional enhancers and cancer predisposition. Cell 154: 11-13, 2013.

27. Jaenisch R and Bird A: Epigenetic regulation of gene expression: How the genome integrates intrinsic and environmental signals. Nat Genet 33 (Suppl): S245-S254, 2003.

28. Irizarry RA, Ladd-Acosta C, Wen B, Wu Z, Montano C, Onyango P, Cui H, Gabo K, Rongione M, Webster M, et al: The human colon cancer methylome shows similar hypo- and hypermethylation at conserved tissue-specific $\mathrm{CpG}$ island shores. Nat Genet 41: 178-186, 2009.

29. Jaffe AE, Murakami P, Lee H, Leek JT, Fallin MD, Feinberg AP and Irizarry RA: Bump hunting to identify differentially methylated regions in epigenetic epidemiology studies. Int $\mathbf{J}$ Epidemiol 41: 200-209, 2012.

30. Li B and Dewey CN: RSEM: Accurate transcript quantification from RNA-Seq data with or without a reference genome. BMC Bioinformatics 12: 323, 2011

31. Holm K, Staaf J, Lauss M, Aine M, Lindgren D, Bendahl PO, Vallon-Christersson $J$, Barkardottir RB, Höglund $M$, Borg $\AA$, et al: An integrated genomics analysis of epigenetic subtypes in human breast tumors links DNA methylation patterns to chromatin states in normal mammary cells. Breast Cancer Res 18: 27, 2016. 
32. Jeschke J, Bizet M, Desmedt C, Calonne E, Dedeurwaerder S, Garaud S, Koch A, Larsimont D, Salgado R, Van den Eynden $\mathrm{G}$, et al: DNA methylation-based immune response signature improves patient diagnosis in multiple cancers. J Clin Invest 127: 3090-3102, 2017.

33. Edgar R, Domrachev M and Lash AE: Gene expression omnibus: NCBI gene expression and hybridization array data repository. Nucleic Acids Res 30: 207-210, 2002.

34. Edge SB and Compton CC: The American joint committee on cancer: The 7th edition of the AJCC cancer staging manual and the future of TNM. Ann Surg Oncol 17: 1471-1474, 2010.

35. Kim SI, Park BW and Lee KS: Comparison of stage-specific outcome of breast cancer based on 5th and 6th AJCC staging system. J Surg Oncol 93: 221-227, 2006.

36. Yu G, Wang LG, Han Y and He QY: clusterProfiler: An R package for comparing biological themes among gene clusters. OMICS 16: 284-287, 2012

37. Ashburner M, Ball CA, Blake JA, Botstein D, Butler H, Cherry JM, Davis AP, Dolinski K, Dwight SS, Eppig JT, et al Gene ontology: Tool for the unification of biology. The Gene Ontology Consortium. Nat Genet 25: 25-29, 2000.

38. The Gene Ontology Consortium: The gene ontology resource: 20 years and still GOing strong. Nucleic Acids Res 47: D330-D338, 2019.

39. Benjamini Y and Hochberg Y: Controlling the false discovery rate: A practical and powerful approach to multiple testing. J R Statist Soc B 57: 289-300, 1995.

40. Lánczky A, Nagy Á, Bottai G, Munkácsy G, Szabó A, Santarpia L and Győrffy B: miRpower: A web-tool to validate survivalassociated miRNAs utilizing expression data from 2178 breast cancer patients. Breast Cancer Res Treat 160: 439-446, 2016.

41. Györffy B, Lanczky A, Eklund AC, Denkert C, Budczies J, Li Q and Szallasi Z: An online survival analysis tool to rapidly assess the effect of 22,277 genes on breast cancer prognosis using microarray data of 1,809 patients. Breast Cancer Res Treat 123: 725-731, 2010.

42. Tuo YL and Ye YF: MGP is downregulated due to promoter methylation in chemoresistant ER+ breast cancer and high MGP expression predicts better survival outcomes. Eur Rev Med Pharmacol Sci 21: 3871-3878, 2017.

43. Sano K, Tanihara H, Heimark RL, Obata S, Davidson M, St John T, Taketani S and Suzuki S: Protocadherins: A large family of cadherin-related molecules in central nervous system. EMBO J 12: 2249-2256, 1993

44. Yagi T and Takeichi M: Cadherin superfamily genes: Functions, genomic organization, and neurologic diversity. Genes Dev 14: $1169-1180,2000$

45. Kawaguchi M, Toyama T, Kaneko R, Hirayama T, Kawamura Y and Yagi T: Relationship between DNA methylation states and transcription of individual isoforms encoded by the protocadherin-alpha gene cluster. J Biol Chem 283: 12064-12075, 2008.

46. Yu JS, Koujak S, Nagase S, Li CM, Su T, Wang X, Keniry M, Memeo L, Rojtman A, Mansukhani M, et al: PCDH8, the human homolog of PAPC, is a candidate tumor suppressor of breast cancer. Oncogene 27: 4657-4665, 2008.

47. Li AM, Tian AX, Zhang RX, Ge J, Sun X and Cao XC: Protocadherin-7 induces bone metastasis of breast cancer Biochem Biophys Res Commun 436: 486-490, 2013.

48. Liu P, Sun M, Jiang W, Zhao J, Liang C and Zhang H: Identification of targets of miRNA-221 and miRNA-222 in fulvestrant-resistant breast cancer. Oncol Lett 12: 3882-3888, 2016.

49. Liu H, Wang G, Yang L, Qu J, Yang Z and Zhou X: Knockdown of long non-coding RNA UCA1 increases the tamoxifen sensitivity of breast cancer cells through inhibition of Wnt/ $\beta$-catenin pathway. PLoS One 11: e0168406, 2016.

50. Mansouri S, Naghavi-Al-Hosseini F, Farahmand L and Majidzadeh AK: MED1 may explain the interaction between receptor tyrosine kinases and ER $\alpha 66$ in the complicated network of Tamoxifen resistance. Eur J Pharmacol 804: 78-81, 2017.

51. Bhatlekar S, Fields JZ and Boman BM: Role of HOX genes in stem cell differentiation and cancer. Stem Cells Int 2018: 3569493,2018
52. Shah M, Cardenas R, Wang B, Persson J, Mongan NP, Grabowska A and Allegrucci C: HOXC8 regulates self-renewal, differentiation and transformation of breast cancer stem cells. Mol Cancer 16: 38, 2017.

53. Lee JY, Hur H, Yun HJ, Kim Y, Yang S, Kim SI and Kim MH: HOXB5 promotes the proliferation and invasion of breast cancer cells. Int J Biol Sci 11: 701-711, 2015.

54. Kamalakaran S, Varadan V, Giercksky Russnes HE, Levy D, Kendall J, Janevski A, Riggs M, Banerjee N, Synnestvedt M, Schlichting E, et al: DNA methylation patterns in luminal breast cancers differ from non-luminal subtypes and can identify relapse risk independent of other clinical variables. Mol Oncol 5: 77-92, 2011.

55. Li Q, Seo JH, Stranger B, McKenna A, Pe'er I, Laframboise T, Brown $M$, Tyekucheva $S$ and Freedman ML: Integrative eQTL-based analyses reveal the biology of breast cancer risk loci. Cell 152: 633-641, 2013.

56. Maston GA, Evans SK and Green MR: Transcriptional regulatory elements in the human genome. Annu Rev Genomics Hum Genet 7: 29-59, 2006.

57. Cardoso F, Costa A, Norton L, Senkus E, Aapro M, André F, Barrios $\mathrm{CH}$, Bergh J, Biganzoli L, Blackwell KL, et al: ESO-ESMO 2nd international consensus guidelines for advanced breast cancer (ABC2)†. Ann Oncol 25: 1871-1888, 2014.

58. Ali S, Rasool M, Chaoudhry H, N Pushparaj P, Jha P, Hafiz A, Mahfooz M, Abdus Sami G, Azhar Kamal M, Bashir S, et al: Molecular mechanisms and mode of tamoxifen resistance in breast cancer. Bioinformation 12: 135-139, 2016

59. Kalyuga M, Gallego-Ortega D, Lee HJ, Roden DL, Cowley MJ, Caldon CE, Stone A, Allerdice SL, Valdes-Mora F, Launchbury R, et al: ELF5 suppresses estrogen sensitivity and underpins the acquisition of antiestrogen resistance in luminal breast cancer. PLoS Biol 10: e1001461, 2012.

60. Mittal MK, Singh K, Misra S and Chaudhuri G: SLUG-induced elevation of D1 cyclin in breast cancer cells through the inhibition of its ubiquitination. J Biol Chem 286: 469-479, 2011.

61. Ingle JN, Liu M, Wickerham DL, Schaid DJ, Wang L, Mushiroda T, Kubo M, Costantino JP, Vogel VG, Paik S, et al: Selective estrogen receptor modulators and pharmacogenomic variation in ZNF423 regulation of BRCA1 expression: Individualized breast cancer prevention. Cancer Discov 3: 812-825, 2013

62. Marino N, Woditschka S, Reed LT, Nakayama J, Mayer M, Wetzel M and Steeg PS: Breast cancer metastasis: Issues for the personalization of its prevention and treatment. Am J Pathol 183: 1084-1095, 2013

63. Mehrotra J, Vali M, McVeigh M, Kominsky SL, Fackler MJ, Lahti-Domenici J, Polyak K, Sacchi N, Garrett-Mayer E, Argani P and Sukumar S: Very high frequency of hypermethylated genes in breast cancer metastasis to the bone, brain, and lung. Clin Cancer Res 10: 3104-3109, 2004.

64. Ostrakhovitch EA and Li SS: NIP1/DUOXA1 expression in epithelial breast cancer cells: Regulation of cell adhesion and actin dynamics. Breast Cancer Res Treat 119: 773-786, 2010.

65. Park SY, Kwon HJ, Choi Y, Lee HE, Kim SW, Kim JH, Kim IA, Jung N, Cho NY and Kang GH: Distinct patterns of promoter $\mathrm{CpG}$ island methylation of breast cancer subtypes are associated with stem cell phenotypes. Mod Pathol 25: 185-196, 2012.

66. Feske S: Calcium signalling in lymphocyte activation and disease. Nat Rev Immunol 7: 690-702, 2007.

67. Svendsen AJ, Gervin K, Lyle R, Christiansen L, Kyvik K, Junker P, Nielsen C, Houen G and Tan Q: Differentially methylated DNA regions in monozygotic twin pairs discordant for rheumatoid arthritis: An epigenome-wide study. Front Immunol 7: 510, 2016.

This work is licensed under a Creative Commons Attribution-NonCommercial-NoDerivatives 4.0 International (CC BY-NC-ND 4.0) License. 